UNIVERSIDADE DE SÃO PAULO

ESCOLA DE ENFERMAGEM DE RIBEIRÃO PRETO

ESTUDO DO ABSENTEÍSMO DOS TRABALHADORES DE ENFERMAGEM EM UMA UNIDADE BÁSICA E DISTRITAL DE SAÚDE DO MUNICÍPIO DE RIBEIRÃO PRETO-SP

GILZA MARQUES DO NASCIMENTO

Dissertação de Mestrado apresentada à Escola de Enfermagem de Ribeirão Preto da Universidade de São Paulo, para concorrer ao título de Mestre, pelo curso de Pós-Graduação em Enfermagem Fundamental do Departamento de Enfermagem Geral e Especializada.

Linha de Pesquisa: Dinâmica da organização dos serviços de saúde e de enfermagem

Ribeirão Preto

2003 
UNIVERSIDADE DE SÃO PAULO

ESCOLA DE ENFERMAGEM DE RIBEIRÃO PRETO

\title{
ESTUDO DO ABSENTEÍSMO DOS TRABALHADORES DE ENFERMAGEM EM UMA UNIDADE BÁSICA E DISTRITAL DE SAÚDE DO MUNICÍPIO DE RIBEIRÃO PRETO-SP
}

\begin{abstract}
Dissertação apresentada à Escola de Enfermagem de Ribeirão Preto da Universidade de São Paulo, para concorrer ao título de Mestre, pelo curso de Pós-Graduação em Enfermagem Fundamental do Departamento de Enfermagem

Geral e Especializada.
\end{abstract}

Orientadora: Prof ${ }^{\mathrm{a}} \mathrm{Dr}^{\mathrm{a}}$ Maria Luiza Anselmi

Ribeirão Preto

2003 


\section{FICHA CATALOGRÁFICA}

\section{Nascimento, Gilza Marques do}

Estudo do absenteísmo dos trabalhadores de enfermagem em uma Unidade Básica e Distrital de Saúde do município de Ribeirão Preto-SP USP, 2003.

118p.

Dissertação de Mestrado, apresentada à Escola de Enfermagem de Ribeirão Preto - USP - Área de concentração: Enfermagem Fundamental. Orientadora: Prof ${ }^{a}$ Dr $^{\mathrm{a}}$ Maria Luiza Anselmi

1. Absenteísmo. 2. Enfermagem. 3. Trabalhadores. 
Data da Defesa:

1

\section{Banca Examinadora}

Prof $^{\mathrm{a}} \mathrm{Dr}^{\mathrm{a}}$ Maria Luiza Anselmi

Julgamento:

Assinatura:

Dra Ana Maria Laus

Julgamento:

Assinatura:

Profa $^{a} r^{a}$ Maria José Bistafa Pereira

Julgamento:

Assinatura: 
Dedico especialmente a Deus, pela maneira maravilhosa com que tem guiado a minha vida. 
Aos meus filhos: Fabio, Felipe e Alana, por tudo de mais belo que representam, sendo fonte de renovação e continuidade. Amo muito vocês!

Ao meu esposo, Jailson, por tudo que compartilhamos durante todos esses anos, pelo incentivo e apoio para alcançar mais este objetivo. 
Agradeço especialmente, a minha orientadora, Profa $\mathcal{D r}^{a}$ Maria Luiza Anselmi, pelo estímulo, competência, serenidade e disponibilidade oferecidos. Muito obrigada por compartilhar todas as dúvidas e ansiedades surgidas durante esta investigação. 


\section{Agradecimentos}

Aos meus pais, Angelina e Modesto, pelo exemplo de luta e perseverança diante das dificuldades da vida. Pelos sólidos valores que me foram passados.

Aos meus filhos, Fabio, Felipe e Alana, pela imensa compreensão das minhas ausências e "impaciências", pelas digitações e assessoria na informática, também pelas "cobran-ças" para o término desta dissertação.

A todos meus familiares, pelo incentivo e carinho.

À Profa Dr $^{a}$ Elisabeth Laus Ribas Gomes, com quem discuti o primeiro estágio do meu projeto de dissertação.

Às Profas Dras Janete Rodrigues da Silva Nakao e Cláudia Benedita dos Santos, pelas valiosas sugestões apresentadas por ocasião do exame de qualificação.

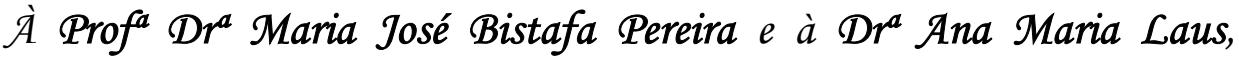
membros da banca examinadora, por aceitarem o convite para ler este trabalho e por contribuírem de maneira significativa na reflexão $e$ melhoria do mesmo.

À Secretaria Municipal de Saúde, na pessoa do Dr. Luis Carlos Raya, pela autorização para realização deste estudo.

Ao Gustavo Perin, chefe da Divisão de Gerenciamento de Pessoal, pela disponibilidade de informações para a construção deste trabalho.

À Denise Beretta Barboza, pela disponibilização de seu material bibliográfico.

Às bibliotecárias, Maria Cristina Manduco Ferreira e Milena Célere, pelo auxílio na revisão das referências bibliográficas. 
Às amigas: Eidi $\mathcal{T}$. Lausmann, Elione F. Souza, Marlene D. Mendes, Simone $\mathcal{P}$. Optiz e Silvana $\mathcal{M}$. Paulino, pela amizade, pelas discussões e ajuda prestada em diversos momentos deste trabalho.

Às funcionárias, Deolinda e Lourdes, da sala de leitura, pela constante colaboração.

Á Débora Ap. Binda, pela competência na digitação deste trabalho.

A todos que, das mais variadas formas, contribuíram direta ou indiretamente para a concretização desta pesquisa. 
"Nos sonhos de cada dia, a certeza de que a vida vale a pena pelas amizades que se tem, pelas lutas vencidase por tudo de novo e de 6om que há para acontecer".

(autor desconhecido) 


\section{SUMÁRIO}

Lista de Abreviaturas

Lista de Tabelas e Figuras

Resumo

Abstract

Resumen

1. TRAJETÓRIA PROFISSIONAL

2. ABSENTEÍSMO: ASPECTOS TEÓRICOS E OPERACIONAIS ........ 7

2.1 Absenteísmo no trabalho de enfermagem ............................... 15

2.2 Absenteísmo: propostas de mensuração .................................... 31

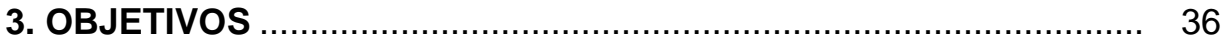

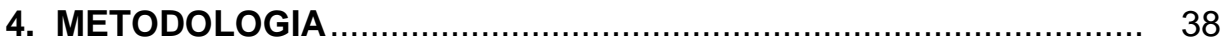

4.1 Tipo de estudo ............................................................... 39

4.2 Local de estudo ............................................................. 39

4.2.1 Organização dos serviços de saúde no município de Ribeirão Preto-SP ................................................... 41

4.2.1.1 A Unidade Básica e Distrital de Saúde "Dr. Ítalo Baruffi" - Castelo Branco.....

4.2.2 A questão do absenteísmo na Secretaria Municipal de Saúde de Ribeirão Preto-SP ............................................ 46

4.3 População........................................................................ 49

4.4 Processo de pesquisa: instrumento, coleta e análise dos dados. 49

4.5 Procedimentos éticos ................................................................ 51

5. RESULTADOS E DISCUSSÃO …............................................. 53

5.1 Índice de Absenteísmo da equipe de enfermagem.......................... 54

5.2 Distribuição dos tipos de ausência não prevista ................................ 76

6. CONSIDERAÇÕES FINAIS......................................................... 95

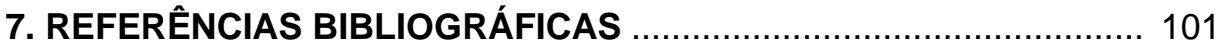

8. ANEXOS 


\section{LISTA DE ABREVIATURAS E SIGLAS}

\begin{tabular}{|c|c|}
\hline AIDS & Síndrome de Imunodeficiência Adquirida \\
\hline \multirow{2}{*}{ CADAIS } & Centro de Apoio ao Desenvolvimento de Assistência \\
\hline & Integral à Saúde \\
\hline CAT & Comunicação para Acidente de Trabalho \\
\hline CLT & Consolidação das Leis do Trabalho \\
\hline COFEN & Conselho Federal de Enfermagem \\
\hline DIR & Divisão Regional de Saúde \\
\hline DST & Doenças Sexualmente Transmissíveis \\
\hline \multirow[t]{2}{*}{ HCFMRP-USP } & Hospital das Clínicas da Faculdade de Medicina de \\
\hline & Ribeirão Preto - Universidade de São Paulo \\
\hline HIV & Vírus da Imunodeficiência Humana \\
\hline IA & Índice de Absenteísmo \\
\hline INSS & Instituto Nacional de Seguro Social \\
\hline IST & Índice de Segurança Técnica \\
\hline NAPS & Núcleo de Assistência Psicossocial \\
\hline \multirow[t]{2}{*}{ NAPS/F } & Núcleo de Assistência Psicossocial para \\
\hline & Farmacodependentes \\
\hline NGA & Núcleo de Gestão Ambulatorial \\
\hline NOB & Norma Operacional Básica \\
\hline PAM & Posto de Atendimento Médico \\
\hline PIB & Produto Interno Bruto \\
\hline PSF & Programa de Saúde da Família \\
\hline SUS & Sistema Único de Saúde \\
\hline
\end{tabular}


SMS

SP

UBS

UBDS

USP
Secretaria Municipal de Saúde

São Paulo

Unidade Básica de Saúde

Unidade Básica e Distrital de Saúde

Universidade de São Paulo 


\section{LISTA DE FIGURAS}

Figura 1. Índice de Absenteísmo de pessoal de enfermagem, segundo período de estudo e categoria profissional em uma UBDS. Ribeirão Preto, agosto/1998 a julho/2002

Figura 2. Índice geral de Absenteísmo (\%) para equipe de enfermagem, segundo período de estudo numa UBDS. Ribeirão Preto-SP, agosto/1998 a julho/2002

Figura 3. Proporção de ausências não previstas, segundo tipo de ausência, na UBDS, agosto/1998 a julho/2002. 


\section{LISTA DE TABELAS}

Tabela 1. Quantitativo médio de pessoal de enfermagem e respectivo incremento (\%), segundo categoria profissional em uma UBDS. Ribeirão Preto, agosto/1998 a julho/2002

Tabela 2. Distribuição das ausências não previstas (em dias), segundo categoria profissional e período em uma UBDS. Ribeirão Preto, agosto/1998 a julho/2002.

Tabela 3. Número médio de pessoal, número de ausências não previstas (em dias) e Índice de Absenteísmo* (IA), segundo categoria profissional e tipo de ausência em uma UBDS. Ribeirão Preto, agosto/1998 a julho/1999.

Tabela 4. Número médio de pessoal, número de ausências não previstas (em dias) e Índice de Absenteísmo* (IA), segundo categoria profissional e tipo de ausência em uma UBDS. Ribeirão Preto, agosto/1999 a julho/2000.

Tabela 5. Número médio de pessoal, número de ausências não previstas (em dias) e Índice de Absenteísmo* (IA), segundo categoria profissional e tipo de ausência em uma UBDS. Ribeirão Preto, agosto/2000 a julho/2001

Tabela 6. Número médio de pessoal, número de ausências não previstas (em dias) e Índice de Absenteísmo* (IA), segundo categoria profissional e tipo de ausência em uma UBDS. Ribeirão Preto, agosto/2001 a julho/2002

Tabela 7. Distribuição do número de dias de ausência e respectivo Índice de Absenteísmo (IA), segundo categoria profissional e período em uma UBDS. Ribeirão Preto, agosto/1998 a julho/2002.

Tabela 8. Distribuição das ausências não previstas (em dias) dos trabalhadores de enfermagem, segundo categoria profissional e tipo de ausência em uma UBDS. Ribeirão Preto, agosto/1998 a julho/1999

Tabela 9. Distribuição das ausências não previstas (em dias) dos trabalhadores de enfermagem, segundo categoria profissional e tipo de ausência em uma UBDS. Ribeirão Preto, agosto/1999 a julho/2000 
Tabela 10. Distribuição das ausências não previstas (em dias) dos trabalhadores de enfermagem, segundo categoria profissional e tipo de ausência em uma UBDS. Ribeirão Preto, agosto/2000 a julho/2001

Tabela 11. Distribuição das ausências não previstas (em dias) dos trabalhadores de enfermagem, segundo categoria profissional e tipo de ausência em uma UBDS. Ribeirão Preto, agosto/2001 a julho/2002

Tabela 12. Distribuição das ausências não previstas (em dias) dos trabalhadores de enfermagem, segundo categoria profissional e tipo de ausência em uma UBDS. Ribeirão Preto, agosto/1998 a julho/2002 


\section{RESUMO}

\section{ESTUDO DO ABSENTEÍSMO DOS TRABALHADORES DE ENFERMAGEM DE UMA UNIDADE BÁSICA E DISTRITAL DE SAÚDE DO MUNICÍPIO DE RIBEIRÃO PRETO-SP}

O absenteísmo tem se tornado problema crucial tanto para as organizações como para os administradores. Suas causas estão ligadas a múltiplos fatores, tornando-o complexo e de difícil gerenciamento. Absenteísmo é a ausência do trabalhador ao serviço, quando se esperava que ele estivesse presente. $\mathrm{Na}$ enfermagem, esse fenômeno vem preocupando os gerentes, uma vez que faltas freqüentes ao trabalho repercutem no quantitativo de recursos humanos, refletindo na qualidade da assistência prestada à clientela. Além disso, o absenteísmo constitui-se variável relevante quando se trata de dimensionar quadro de pessoal para os serviços. Este estudo foi desenvolvido com base no quadro conceitual desenvolvido por Gaidzinski (1998), no qual as ausências são classificadas em previstas e não previstas. Ausências previstas são aquelas de direito do trabalhador, podendo ser, planejadas com antecedência como férias, folgas e feriados. As ausências não previstas são as que efetivamente caracterizam o absenteísmo, pelo seu caráter imprevisível, entre elas: faltas abonadas e injustificadas; licenças médicas; maternidade; paternidade; acidente de trabalho; outras licenças amparadas por lei e/ou de direito do servidor (nojo, gala, congresso). Tratase de um estudo retrospectivo, exploratório e descritivo, com abordagem quantitativa cujos objetivos_foram: mensurar o absenteísmo dos

Excluído: Estas ausências podem ser classificadas em previstas e não previstas. ๆ

As

Excluído: a

Excluído: e

Excluído: na escala

Excluído: e algumas licenças.

Excluído:

O presente estudo tem como Quantatia culos 
trabalhadores de enfermagem em uma Unidade Básica e Distrital de Saúde (UBDS) de um município de grande porte no interior paulista, no período de agosto de 1998 a julho de 2002; descrever a distribuição dos tipos de ausências não previstas desses trabalhadores._A população constituiu-se dos trabalhadores de enfermagem (enfermeiros, técnicos e auxiliares de enfermagem) que, no período estudado, encontravam-se alocados na UBDS selecionada para a investigação._Os dados relativos ao número de dias de ausências não previstas foram coletados junto à Divisão de Gerenciamento de Pessoal da Secretaria Municipal de Saúde e transcritos para uma planilha. Para o cálculo do Índice de Absenteísmo (IA), adotou-se equação proposta por Pavani (2000). O índice geral de absenteísmo encontrado foi de $6,61 \%$, o que significa que do tempo total de trabalho esperado da equipe $\underline{\text { de enfermagem nos quatro anos, aproximadamente, } 7 \% \text { ficou comprometido }}$ devido às ausências não previstas. Em relação às categorias de trabalhadores, obteve-se 5,37\% de absenteísmo para enfermeiros, 8,06\% para técnicos e 6,82\% para auxiliares de enfermagem.0 tipo de ausência não prevista predominante, foi a licença para tratamento de saúde com um percentual geral de $46,94 \%$; sendo de $54,43 \%, 41,52 \%$ e $45,75 \%$ para enfermeiros, técnicos e auxiliares de enfermagem, respectivamente. Partindo da premissa de que é através do trabalho desenvolvido pelas pessoas que se alcançam os resultados propostos pela organização, neste caso, atender às necessidades de saúde da população, entende-se que o absenteísmo é essencialmente um problema de gestão e, neste sentido, cabe à gerência o acompanhamento e monitoramento da assiduidade de

\section{Excluído: ?}

Trata-se de um estudo retrospectivo, exploratório e

descritivo, que se utilizou da abordagem quantitativa.

Excluído: de agosto de 1998 a julho de 2002

Excluído: ๆ

Excluído: para o levantamento das ausências não previstas foi obtido

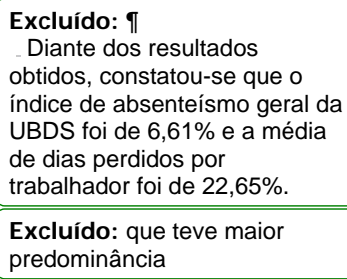

Excluído: que teve maior predominância

Excluído: a categoria que apresentou maior índice de absenteísmo foi o técnico de enfermagem com $8,06 \%$. 
seus trabalhadores.

PALAVRAS-CHAVE: Absenteísmo; Enfermagem; Trabalhadores. 


\section{ABSTRACT \\ STUDY ON THE ABSENTEEISM OF NURSING WORKERS AT A DISTRICT BASIC HEALTH UNIT AT THE MUNICIPALITY OF RIBEIRÃO PRETO, SP, BRAZIL}

The absenteeism is becoming a crucial problem for organizations as well for managers. Its causes are linked to multiple factors and that is why it is so complex and difficult to manage. Absenteeism is the absence of workers, when they were expected to be present. In Nursing, this phenomenon is a concern for managers as the frequent absences affect the quantitative human resources, reflecting in the quality of the care provided to patients. In addition, absenteeism is a relevant variable in order to dimension the staff. This study was developed based on the Gaidzinski (1998) framework, in which the absences are classified as expected and non expected. The expected absences are the ones that can be planed before, such as leaves, vacations and holidays. The non expected absences are the ones that effectively characterize the absenteeism due to its non expected character, among them: non justified absences, medical leaves, family leaves, occupational accidents and other leaves that are included among the workers' rights. This is a retrospective, exploratory and descriptive study based on a quantitative approach with the aims of: measuring the absenteeism among the nursing workers at a District Basic Health Unit of a large municipality in the state of São Paulo from August, 1998 to July, 2002; describing the types distribution of non-expected absences among these 
workers. The population was formed by nursing workers (nurses, nursing technicians and auxiliaries) that worked at the Unit in the above mentioned time period. Data related to the number of non expected absences were collected at the Human Resources Division of the Municipal Health Department and transcribed in a worksheet. To calculate the rate of absenteeism, the author adopted the equation proposed by Pavani (2000). The general rate of absenteeism was of $6.61 \%$, meaning that from the total nursing team expected work in four years, approximately, $7 \%$ was impaired due to non expected absences. With respect to the categories of workers, $5.37 \%$ was the rate of absenteeism for nurses, $8.06 \%$ the rate for technicians and $6.83 \%$ for nursing auxiliaries. The predominant type of non expected absenteeism was the medical leave, representing $46.94 \%$ of the total; considering this leave, $54.43 \%$ was the rate for nurses, $41.42 \%$ for nursing technicians and $45.75 \%$ for nursing auxiliaries. Based on the idea that the organization achieves its goals through the work developed, in this case, to meet the population care needs, the absenteeism must be understood as a managerial problem and therefore, the managers must follow and monitor the diligence of their workers.

KEY WORDS: absenteeism, nursing, workers 


\title{
RESUMEN
}

\section{ESTUDIO DEL ABSENTISMO DE TRABAJADORES DE ENFERMERÍA DE UNA UNIDAD BÁSICA Y DISTRICTAL DE SALUD DE LA MUNICIPALIDAD DE RIBEIRAO PRETO - SP, BRASIL}

\begin{abstract}
El absentismo es considerado un problema crucial para las organizaciones y para los administradores. Sus causas están ligadas a múltiplos factores, resultando en un problema complejo y de difícil gestión. E absentismo es la ausencia del trabajador al servicio, cuando se esperaba que la persona estuviera presente. En la enfermería, este fenómeno está preocupando los gerentes una vez que las ausencias frecuentes al trabajo repercuten en el cuantitativo de recursos humanos, reflexionando en la calidad de la asistencia prestada a la clientela. Además de eso, el absentismo se constituye en una variable relevante cuando se trata de dimensionar el cuadro de personal para los servicios. Este estudio fue desarrollado con base en el cuadro conceptual desarrollado por Gaidzinski (1998), en el cual las ausencias son clasificadas como previstas o no previstas. Ausencias previstas son las de derecho del trabajador y pueden ser planeadas con antecedencia como vacaciones, huelgas y feriados. Las ausencias no previstas son las que efectivamente caracterizan el absentismo, por su carácter imprevisible como: ausencias abonadas y no justificadas, licencias médicas, maternidad, paternidad, accidentes de trabajo; otras licencias amparadas por ley y/o derecho del trabajador. Se trata de un estudio retrospectivo, exploratorio y descriptivo, con abordaje
\end{abstract}


cuantitativo cuyos objetivos fueron: mensurar el absentismo de los trabajadores de enfermería en una Unidad Básica y Districtal de Salud de una municipalidad de grande porte en el interior del estado de São Paulo en el periodo entre agosto de 1998 y julio de 2002; describir la distribución de los tipos de ausencias no previstas de los trabajadores. La población es formada por los trabajadores de enfermería (enfermeros, técnicos y auxiliares de enfermería) que en el periodo estudiado estaban trabajando en la Unidad mencionada. Los datos relativos al número de días de ausencias no previstas fueron recoleccionados junto a la División de Gestión del Personal de la Secretaria Municipal de Salud y transcriptos para una planilla. Para cálculo del índice de absentismo (IA) fue adoptada una ecuación propuesta por Pavani (2000). El índice general de absentismo fue de 6.61\%, significando que del tiempo total de trabajo esperado del equipo de enfermería en los cuatro años, cerca de $7 \%$ fue comprometido debido a ausencias no previstas. En relación a las categorías de trabajadores, la autora verificó 5.37\% de absentismo para enfermeros, 8.06\% para técnicos y 6.82\% para auxiliares de enfermería. El tipo de ausencia no prevista predominante fue la licencia para tratamiento de salud con un porcentaje general de $46.94 \%$; siendo de $54.43 \%, 41.52 \%$ y $45.75 \%$ para enfermeros, técnicos y auxiliares de enfermería, respectivamente. Considerando la premisa de que es a través del trabajo desarrollado por las personas que se alcanzan los resultados propuestos por la organización, en este caso, atender las necesidades de salud de la población, se comprende que el absentismo es esencialmente un problema de gestión y así, cabe a la 
gerencia el acompañamiento y control de la asiduidad de sus trabajadores.

PALABRAS-CLAVE: absentismo, enfermería, trabajadores 
1. TRAJETÓRIA PROFISSIONAL<smiles>C=C=C=C=C</smiles> 
Após completar o curso de graduação em Enfermagem, em 1976, tive a oportunidade de trabalhar em um hospital público de grande porte da cidade de São Paulo, inicialmente, como enfermeira assistencial do Pronto-Socorro e, posteriormente, do Centro Cirúrgico e Centro de Recuperação Pós-Anestésica.

Completados quatro anos de trabalho nesses setores, fui promovida ao cargo de supervisora de enfermagem, convivendo daí por diante com transtornos desencadeados pelas ausências dos funcionários sob minha responsabilidade. Por tratar-se de setores complexos e com rotinas peculiares, sentia dificuldades em suprir as faltas dos funcionários. Os profissionais de enfermagem dos outros setores, quando remanejados para cobrir as ausências, alegavam desconhecimento das tarefas e rotinas.

Uma experiência diferente da realidade hospitalar deu-se na Secretaria de Higiene e Saúde, também em São Paulo, em 1983, num Departamento de Saúde da Comunidade, quando fui convidada para auxiliar na supervisão dos Postos de Saúde. Constatei haver um elevado número de afastamentos por parte dos funcionários devido a licenças médicas, provocando algumas vezes situações caóticas na dinâmica do trabalho da unidade, uma vez que a essas ausências somavam-se aquelas referentes às férias e licenças especiais de outros servidores. Vale ressaltar que nem sempre as chefias eram avisadas com antecedência sobre essas licenças, tomando conhecimento da sua duração somente após publicação em Diário Oficial.

No ano de 1989, assumi a gerência de enfermagem de um 
hospital privado de Ribeirão Preto, interior do estado de São Paulo. Essa instituição possuía 72 leitos para atender às especialidades de ginecologia e obstetrícia, pediatria, clínica médica e cirurgia geral. O quadro de enfermagem era composto por 92 funcionários e o atendimento era destinado a pacientes particulares e conveniados, sendo sua subvenção provinda de uma medicina de grupo.

Nessa época, a organização passava por uma reestruturação e a direção entendia que havia um número excessivo de funcionários; assim solicitou um redimensionamento do pessoal com intuito de reduzir os custos hospitalares no que se referia à folha de pagamento do setor de enfermagem.

$\mathrm{Na}$ ocasião, adotei para o dimensionamento do pessoal de enfermagem o método tradicional proposto pela Associação Americana de Hospitais (1956), cuja equação estabelece para cobertura de ausências o percentual de 20\%, também denominado Índice de Segurança Técnica (IST).

Nesse momento, não havia na instituição qualquer parâmetro que informasse o índice de absenteísmo existente. Os resultados obtidos no estudo evidenciaram que o quadro de pessoal de enfermagem vigente era suficiente, entretanto, no cotidiano do trabalho havia dificuldade em alocar os funcionários no sentido de garantir a totalidade de atividades desenvolvidas. Tais fatos inquietavam-me, gerando algumas suposições entre elas a de que o percentual para cobertura de ausência (20\%), segundo a equação adotada, não estaria adequada ao contexto daquele hospital. 
Observando que as faltas ao trabalho eram freqüentes, recorria à administração para a autorização de horas extras, porém, nem sempre isso era possível devido à contenção de gastos ou falta de disponibilidade de funcionários para a prorrogação de horários. Quando não conseguia reposição nas condições referidas, o trabalho era realizado com repercussão negativa seja na equipe de enfermagem, que alegava sobrecarga de trabalho, seja com os pacientes e acompanhantes que relatavam demora no atendimento, assim como na equipe médica que se queixava dos atrasos na realização dos procedimentos de enfermagem.

A partir de 1990, concomitante ao trabalho hospitalar comecei a atuar em uma Unidade Básica e Distrital de Saúde que apresentava características diferentes na organização do trabalho de enfermagem, entretanto os problemas relacionados às ausências de funcionários foram vivenciados de maneira análoga. Freqüentemente havia problemas devido às faltas inesperadas do pessoal de enfermagem, tornando-se necessário realizar remanejamentos na escala, solicitar aos funcionários a prorrogação de horário e, em alguns casos, solicitar à gerência do serviço, autorização para convocar funcionários por hora extra.

No final de 1999 e, nos anos de 2000 e 2001, tendo já me desligado da área hospitalar, fui várias vezes convocada pela Secretaria Municipal de Saúde para cumprir horas extras em outras unidades de saúde. Essas convocações eram necessárias a fim de cobrir colegas que se encontravam afastados por licença médica, férias ou mesmo devido às vagas existentes e não supridas no quadro de enfermeiros. Através dessa 
experiência pessoal, pude constatar que a situação era semelhante nesses outros locais de trabalho e, em determinadas ocasiões, devido ao contingente reduzido de pessoal, foram suspensas algumas atividades dentre elas visita domiciliária e curativos.

Observava que, em alguns casos, as faltas, embora estivessem amparadas por atestado médico, não estavam ligadas à doença e sim ao descontentamento do funcionário em relação à escala, ao desentendimento com colegas e/ou, ainda ao enfrentamento à chefia por não terem sido atendidos em suas solicitações de mudança de turno, setor, etc.

Ao longo dessa trajetória profissional nos serviços de saúde (hospitalar e ambulatorial), busquei permanentemente atualização de conhecimento e informações que contribuíssem para a minha prática.

A oportunidade para aprofundar conhecimentos e buscar respostas a algumas inquietações deu-se em 2000, quando realizei o processo de seleção ao Programa de Pós-Graduação em Enfermagem Fundamental. Tendo sido aprovada, iniciei as disciplinas em 2001, as quais, gradativamente, motivaram-me para o estudo de temas relacionados à gerência de recursos humanos em enfermagem, uma vez que este tem sido o campo predominante de minha atuação profissional.

Um dos conteúdos abordados em disciplina do programa foi o do dimensionamento de pessoal de enfermagem com destaque para o índice de absenteísmo, que traduz o quantitativo de pessoal a ser acrescido ao quadro para cobertura das ausências. Caso este índice seja 
subestimado, poderá definir-se um quadro de pessoal insuficiente de modo a comprometer a qualidade do cuidado prestado ao cliente, desorganização do trabalho e diminuição da produtividade; se for superestimado poderá acarretar ociosidade e elevação dos custos.

A vivência profissional, ao longo desses anos, seja como gerente do serviço de enfermagem seja como enfermeira assistencial tem sugerido que as ausências no trabalho pelo pessoal de enfermagem representam ainda uma questão crítica com sérias repercussões na assistência à saúde da população e no grupo de trabalho.

Este estudo estará focalizando o absenteísmo do pessoal de enfermagem em uma Unidade Básica e Distrital de Saúde (UBDS), e para tanto torna-se necessário explorar os aspectos teóricos e operacionais desse fenômeno. 
2. ABSENTEÍSMO: ASPECTOS TEÓRICOS E OPERACIONAIS

\author{
2. ABSENTEISMO: ASPECTOS TEORICOS E OPERACIONAIS
}


O absenteísmo tem se tornado um problema crucial para as organizações e administradores. Suas causas estão ligadas a múltiplos fatores que o tornam complexo e de difícil gerenciamento.

Seu efeito negativo remonta ao período industrial, onde as ausências dos trabalhadores diminuíam a produção, repercutindo diretamente na economia. Ele ocasiona não só custos diretos, mas também indiretos, representados pela diminuição da produtividade, redução da qualidade e problemas administrativos (Sobrinho, 2002).

Várias abordagens e definições aparecem na literatura para a expressão absenteísmo. Esse termo originou-se da palavra "absentismo" aplicada aos proprietários rurais que abandonavam o campo para viver na cidade. No período industrial, esse termo foi aplicado aos trabalhadores que faltavam ao serviço (Quick \& Lapertosa, 1982).

Para Chiavenato (1997), o absenteísmo refere-se às ausências nos momentos em que os empregados deveriam estar trabalhando normalmente. O autor amplia o conceito dizendo que é o somatório dos períodos em que os empregados de determinada organização ausentam-se do trabalho, incluindo os atrasos.

Magalhães et al. (1995) definem o absenteísmo como sendo as ausências ao trabalho devido a licenças, férias e faltas.

Para Jorge (1995), absenteísmo representa as ausências ao trabalho por faltas e licenças médicas, ou seja, ausências não programadas. As férias e folgas são excluídas por serem consideradas ausências planejadas dentro de uma jornada de trabalho legal. 
Behrend \& Pocock (1976) entendem que o absenteísmo não constitui um sintoma de inquietude social tão espetacular como as greves, todavia o volume de tempo perdido é superior. Este autor define o absenteísmo como sinônimo de ausência voluntária ao trabalho. Na prática, corresponde às ausências dos trabalhadores que não se apresentam ao trabalho, alegando pretextos vazios ou sem alegar qualquer razão para a falta.

Segundo Gaidzinski (1998), absenteísmo é caracterizado pelas ausências não previstas, devido às faltas, às licenças e às suspensões. A autora exclui neste conceito as ausências por folgas, férias e licenças programadas. Tal definição é compactuada por outros autores como: Mattia (1998), Belém \& Gaidzinski (1998), Echer et al. (1999), Tanos et al. (2000) e Pavani (2000).

Quick \& Lapertosa (1982) entendem que o absenteísmo pode ser voluntário ou involuntário, representando tanto as ausências ao trabalho por razões particulares quanto aquelas justificadas por problemas de saúde e, ainda, as faltas legais ocasionadas por doação de sangue, serviço militar, licença gestação, nojo e gala. Por último, o absenteísmo compulsório que resulta do impedimento de comparecer ao trabalho por suspensão, prisão ou outro motivo que não permita a presença do trabalhador ao seu serviço.

Nesse conceito abrangente Sobrinho (2002) diz que o absenteísmo é a ausência ao trabalho por qualquer razão: doenças, direitos legais, fatores sociais, fatores culturais e acidentes de trabalho.

$\mathrm{Na}$ revisão da literatura, encontramos, portanto, vários 
conceitos e abordagens referentes ao absenteísmo, que são condicionados pela valorização de diferentes aspectos do fenômeno, assim temos diversas definições para o mesmo termo.

As causas das ausências não previstas de acordo com McDonald \& Shaver (1981) podem ser classificadas em três categorias.

As causas intrínsecas estão relacionadas à natureza e condições do trabalho e refletem a satisfação do trabalhador, entre elas:

- o trabalho em si;

- supervisão ineficiente;

- falta de controle;

- sobrecarga de trabalho e exaustão física.

As causas extrínsecas estão principalmente relacionadas às políticas de pessoal da organização:

- políticas de pessoal condolentes com as faltas;

- políticas de pessoal liberais em fornecer licença de saúde;

- falta de canais de comunicação da administração;

- falta de seleção, treinamento e orientação adequados;

- falta de perspicácia em alocar o funcionário em setores apropriados;

- baixos salários e condições de trabalho.

As causas de personalidade dizem respeito ao comportamento do trabalhador:

- empregados que criam conflito entre os membros do grupo;

- personalidade mais propensa às faltas como: hipocondríaco, 
imaturo, fugitivo, abusivo e desmotivado;

- problemas pessoais relacionados ao abuso de droga e álcool.

Os fatores desencadeantes do absenteísmo são classificados em três tipos, segundo Meira (1982):

1. Fatores naturais, como condições climáticas e epidemiológicas;

2. Fatores socioeconômicos como conjuntura econômica, sexo, idade, estado civil, categoria, tempo de empresa, condições de trabalho e nível salarial;

3. Fatores inerentes à própria empresa, isto é, sua política, pessoal, porte, supervisão, chefia e benefícios implantados nas áreas de assistência médica, condução e alimentação.

Couto (1987) alerta sobre a multifatoriedade das causas que levam ao absenteísmo, classificando-as em: fatores de doença, de trabalho, sociais, culturais e de personalidade.

(...)o absenteísmo é determinado por vários fatores
dialeticamente interligados, a saber: condições de saúde
pessoal, condições sociais que afetam o trabalho,
condições do ambiente de trabalho e atitudes frente ao
trabalho, que refletem a exploração econômica e
dominação ideológica (Alves, 1996, p. 5).

Vários autores como Couto (1987); Alves (1996); Anselmi et al. (1997) e Chiavenato (1997) acreditam que a etiologia do absenteísmo tem muito a ver com as condições de trabalho encontradas nas empresas. estilo de liderança e controle, a repetitividade das tarefas, o ambiente de trabalho e a falta de integração entre os funcionários, podem levar à desmotivação e ao desestímulo dos trabalhadores, e desse modo provocam 
impacto na assiduidade ao trabalho.

Song et al. (1997) efetuaram um estudo comparativo das ausências dos trabalhadores que desenvolviam atividades em empresas com administrações burocráticas e participativa. Notaram uma diminuição na taxa de ausências não previstas nos locais onde o gerenciamento é compartilhado e os trabalhadores dispõem de maior autonomia. Esses autores consideram que esse tipo de gerenciamento aumenta a satisfação e a motivação do trabalhador, diminuindo o absenteísmo.

De maneira peculiar, o absenteísmo ligado às enfermidades alcança altos índices nas organizações, obrigando os administradores a despender altas somas com auxílio-doença. Danatro (1997) salienta que, nos últimos 25 anos, houve um aumento de 30\% nos afastamentos por doenças em todos os países industrializados, apesar de melhorias na oferta e qualidade da assistência à saúde e condições socioeconômicas.

O mesmo autor é enfático em declarar que este é um problema persistente e em vias de se agravar em muitas partes do mundo.

Na União Européia, o absenteísmo devido à incapacidade para o trabalho por doença tem um custo total estimado entre 1,5 a $4 \%$ do PIB, o que é equivalente à sua taxa de crescimento econômico em um ano (Graça, 1999).

O ônus financeiro do absenteísmo foi estudado por Reid \& Smith (1993) que apontaram para o valor superior a 40 bilhões de dólares americanos gastos anualmente pelas companhias de seguros americanas com os ausentes ao trabalho. 
No Brasil, várias são as dificuldades encontradas para estudar e quantificar o absenteísmo por doença e em conseqüência não há como precisar o ônus econômico acarretado pelas ausências ao trabalho (Nogueira \& Azevedo, 1982).

Esse fato tem preocupado os administradores em vários segmentos empresariais devido à sua repercussão e abrangência, gerando prejuízo na forma de desenvolvimento do trabalho, aumento dos custos de produção e da previdência social, efeitos negativos na moral dos trabalhadores e diminuição da qualidade e produtividade (Nogueira \& Azevedo, 1982; Couto, 1987; Ceria, 1992 e Danatro, 1997).

Com o objetivo de reduzir o absenteísmo, aumentar a produtividade e proporcionar maiores lucros, empresas multinacionais de grande porte ligadas a outras áreas produtivas têm investido altas somas com programas que visam à melhoria da qualidade de vida dos seus funcionários.

Estima-se que, para cada dólar investido em programas de atenção à saúde do trabalhador, ocorra uma economia de quatro dólares em despesas com assistência médica (A busca..., 1998).

Depoimentos de gerentes de enfermagem de hospitais brasileiros demonstram estar preocupados também em proporcionar boa qualidade de vida e preservar a saúde física e mental dos profissionais de enfermagem. Reconhecendo o desgaste diário do exercício profissional, o estresse e conflitos pessoais enfrentados pela equipe, foram implantadas medidas com vistas à integração social, desenvolvimento profissional, 
incentivo à saúde dos trabalhadores e adequação de recursos humanos. Estas estratégias têm como meta garantir a qualidade da assistência, gerar produtividade e evitar o absenteísmo (Como eu cuido... 2001).

McDonald \& Shaver (1981) propõem alguns passos para um programa de controle do absenteísmo, a saber:

- manter um processo de coleta de dados efetivo, confiável e compreensível acerca das ausências, sendo o supervisor imediato o elemento-chave para identificação das causas;

- detectar os padrões de cada falta e classificá-la segundo relação com doenças ou razões particulares;

- adotar políticas de auditorias junto ao pessoal, estabelecendo e comunicando o posicionamento da chefia em relação às ausências, tratando de maneira justa e constante todos os empregados;

- elaborar planos para avaliar as licenças justificadas por doença. Em média, para 50\% das faltas o motivo alegado são as doenças, mas muitas vezes este não é o motivo verdadeiro da ausência. $O$ trabalhador encontra uma maneira de camuflar as reais causas, por entender que a justificativa por doença é a mais aceita pela chefia.

- desenvolver uma política de disciplina progressiva. É essencial haver uma disciplina para as ausências. Os empregados devem conhecer de antemão a conseqüência que irão receber pelo nãocomparecimento ao trabalho. Essas medidas devem começar com advertência oral, escrita, suspensão sem pagamento e por último, demissão. Essas punições devem ser registradas. 
Por outro lado, os funcionários assíduos devem ser recompensados, tanto monetariamente como através de elogios públicos.

No trabalho de enfermagem, o absenteísmo também constitui um fenômeno presente com repercussões tanto na qualidade da assistência prestada como na produtividade. Tais aspectos serão abordados a seguir.

\subsection{Absenteísmo no trabalho de enfermagem}

Para discutir o absenteísmo no trabalho de enfermagem, realizaremos uma retrospectiva histórica do desenvolvimento da profissão articulada ao tema de estudo.

O modelo industrial capitalista gerou uma nova concepção do objeto de trabalho em saúde. Os procedimentos voltaram-se para a cura do corpo a fim de recuperar a força de trabalho. O desenvolvimento da indústria requeria cidadãos saudáveis para o processo produtivo. Nesse contexto, a enfermagem institucionalizou-se enquanto profissão, em meados do século XIX. O surgimento da enfermagem moderna, representada na figura de Florence Nightingale, conformou-se dividida em duas categorias de trabalhadores, uma que executa 0 cuidado e outra que 0 gerencia/administra. Neste sentido, uma das características marcantes da profissão foi a reprodução da divisão social e técnica; na qual as atividades de supervisão e ensino eram exercidas pelas ladies nurses provenientes da alta classe social, e as atividades de cuidado direto ao paciente, executadas pelas nurses que possuíam um nível socioeconômico inferior (Almeida \& 
Rocha, 1986). Além disso, o exercício desse trabalho era desenvolvido predominantemente pelas mulheres. Assim, o trabalho da enfermagem foi organizado, sistematizado e normatizado com base nos princípios da hierarquia e disciplina oriundos da organização religiosa e militar.

Hoje, essa divisão ainda se mantém, pois os atos mais intelectuais ficam com a enfermagem de nível superior, enquanto os trabalhos manuais, considerados menos qualificados, são realizados pelos profissionais de nível médio (Aquino et al., 1993). Outro aspecto que caracteriza essa divisão é que, ainda hoje, o trabalho de enfermagem continua sendo desenvolvido predominantemente por mulheres. Segundo estudo publicado pelo Ministério da Saúde, em 1996, do pessoal de enfermagem empregado em todos os setores da economia, 85,26\% são mulheres (Brasil,1996).

Spíndola (2000) comenta que após a Revolução Industrial a mulher deixou o espaço privado e passou a ocupar o lugar público, assumindo, assim, uma profissão. Essa opção pelo trabalho se fez em carreiras que mais se aproximassem das características femininas e com atividades compatíveis com suas habilidades. Assim, a enfermagem é vista como uma continuidade do cuidado que as mulheres praticavam na comunidade e com seus familiares.

A profissão de enfermagem esteve, portanto, sempre marcada por conteúdos fortemente ideológicos, atribuindo-se às mulheres uma aptidão inata para cuidar dos outros, aptidão essa que não estaria presente no gênero masculino (Aquino et al., 1993). 
O número de mulheres continua a crescer no mercado de trabalho como forma de aumentar a renda familiar (Oguisso, 1998). Seus salários fazem parte integrante e imprescindível do sustento da casa, sendo hoje, muitas vezes, a única fonte de renda familiar. Esse fato tem sido uma constante nas famílias, devido à crise econômica e desemprego vivido pelos homens.

Esse procedimento provocou alterações significativas em seu cotidiano, pois além das atividades laborais a mulher desempenha seu papel social de esposa, dona de casa e mãe, atribuições que demandam uma segunda jornada de trabalho (Angelo \& Marziale, 1998).

Investigações têm sido realizadas sobre alguns aspectos da realidade profissional da mulher e o absenteísmo, mostrando que este se dá pelo acúmulo de tarefas, pois após terminarem a jornada de trabalho formal nas empresas, essas profissionais se deparam com um vasto leque de atividades domésticas e familiares a serem solucionadas (Alves, 1996).

Nogueira \& Azevedo (1982) apontam a relação existente entre o sexo feminino e o absenteísmo, ressaltando a dupla atividade na indústria e no lar, o que pode implicar em sobrecarga física, preocupações e pouco repouso, desencadeando doenças nervosas e mentais.

Outra característica relevante da equipe de enfermagem diz respeito à idade dos trabalhadores. A idade média destes é de 36 anos, sendo que aproximadamente $61 \%$ encontra-se na faixa etária entre 30 e 49 anos (Brasil,1996). Considerando-se a predominância de mulheres no conjunto da força de trabalho em enfermagem, muitas profissionais 
encontram-se na fase reprodutiva, ausentando-se do trabalho em diferentes fases do ciclo gravídico puerperal ou para cuidar dos filhos (Steagall-Gomes, 1986; Lopes, 1992; Jorge, 1995).

Estudo realizado por Miller \& Norton (1986), com a finalidade de identificar as variáveis que contribuem para o absenteísmo, encontrou que $80 \%$ das ausências ao trabalho relatadas pelas mulheres, decorrem da necessidade de cuidar dos filhos, da precariedade de infra-estrutura doméstica por não ter com quem deixá-los, principalmente quando eles adoecem. Os autores apontam ainda o grande conflito das mulheres entre os papéis desempenhados como mães e trabalhadoras e as exigências em conciliar o trabalho com as necessidades da família.

Fatores relevantes para o absenteísmo das mulheres ao trabalho foram enfocados por Lee \& Ericksen (1990), entre eles: a responsabilidade pelo cuidado com crianças, a provisão de cuidados dispensados aos idosos e companheiros.

Uma outra variável, citada por Danatro (1997), que intensifica o problema do absenteísmo é o fato do profissional possuir múltiplos empregos, realidade que persiste na enfermagem.

Os profissionais dessa área se vêem pressionados a ter muitas vezes duplo ou triplo vínculo empregatício devido aos salários aviltantes, incompatíveis com a dignidade de suas atividades (Robazzi \& Marziale, 1999).

Importante ressaltar a remuneração salarial dos trabalhadores de enfermagem em nosso país. Mesmo o indivíduo possuindo dois 
empregos, privando-se de lazer e do convívio familiar não atinge um salário que Ihe dê condição satisfatória de vida (Nakao et al., 1986).

Freqüentemente, os profissionais de enfermagem necessitam assumir mais de um emprego. Os duplos encargos experimentados pelas mulheres não constituem busca de realização profissional ou opção pessoal, mas uma necessidade relacionada à manutenção das condições de sobrevivência delas próprias e da família. No entanto, essa situação é difícil, pois o trabalho é desgastante fisicamente, além do que representa a certeza de estar quase sempre ausente de casa (Alves, 1996; Santos, 1999).

Por um lado, a manutenção de dois empregos, mesmo resultando em maior cansaço, possibilita a sobrevivência do trabalhador/família. Por outro lado, acaba induzindo o funcionário a ausentar-se com maior freqüência ao trabalho (Robazzi et al., 1990).

O trabalho de Valtorta et al. (1985) também demonstra que as causas de ausências têm componentes culturais e sociais marcantes. Essa pesquisa, realizada junto a servidores de um hospital, incluindo a equipe de enfermagem, aponta como fatores explicativos do absenteísmo, a predominância do sexo feminino na profissão e a necessidade que elas têm em exercer outra atividade profissional para complementar a renda familiar. Ainda é relatado pelos autores as dificuldades encontradas em ascender na carreira e a sobrecarga de atividades como circunstâncias agravantes.

O modo de produção capitalista, vigente no Brasil, tem pressionado os trabalhadores para o estabelecimento de duplo vínculo empregatício e a realização de horas extras que atende tanto as 
organizações que trabalham com um quadro de pessoal enxuto como complementa os baixos salários dos trabalhadores. Dessa forma, essa reciprocidade perversa estabelecida pelo capital transforma em vítima os trabalhadores que em busca de um ganho maior são sobrecarregados física e emocionalmente, ocasionando muitas vezes doenças que os obriga a ausentarem-se do trabalho (Alves, 1996).

Nos estudos acerca do absenteísmo, uma das abordagens predominantes é a da saúde ocupacional, uma vez que o adoecimento no trabalho tem sido uma causa relevante.

Barboza (2001) comenta que a Revolução Industrial promoveu o surgimento de um processo produtivo, no qual o homem deixa o ambiente familiar e passa para o ambiente industrial, enfrentando condições impróprias para as suas atividades. Os trabalhadores ficam expostos às novas tecnologias industriais, evidenciando assim a correlação entre condições de trabalho e saúde do trabalhador.

Laurel \& Noriega (1989) analisaram o processo de trabalho e sua relação com a saúde e destacaram que há grande desgaste por parte dos operários, citando que as doenças causadas pelo trabalho podem ser somáticas, psicossomáticas e psíquicas. Estas doenças são originárias das diversas cargas de trabalho a que ficam expostos, sejam elas de natureza física, química, tensão nervosa, ritmo do trabalho e repetitividade das tarefas.

No estudo das relações entre saúde/doença/trabalho na área de enfermagem, os prejuízos à saúde física e mental decorrem das 
atividades realizadas em extensas jornadas de trabalho, do ritmo acelerado da produção desencadeado por excesso de tarefas; da realização de ações repetitivas e baixa remuneração. $O$ trabalho desempenhado nessas condições deixa de significar satisfação, ganhos materiais e serviços sociais úteis, passando a representar sofrimentos, exploração, doença e até morte (Barboza, 2001).

A repercussão de fatores do ambiente de trabalho na saúde mental das pessoas é descrita por Dejours (1992). Segundo este autor, a organização moderna do trabalho, o ritmo, a tecnologia, o medo, a ansiedade, a pressão da chefia e outros causam um sofrimento escondido, de natureza psíquica.

Com o objetivo de explicar o absenteísmo na enfermagem, Larocque (1996) desenvolveu pesquisa em um hospital canadense com base no modelo teórico causal proposto por Brooke (1986). O modelo parte do princípio de que certos fatores agem diretamente sobre a satisfação no trabalho que por sua vez influenciam o absenteísmo. Em seus resultados identificou que as condições de trabalho, o trabalho em si (tarefas), o grau de autonomia, as relações com colegas, as políticas organizacionais e o estilo de liderança da enfermeira-chefe representam fatores para a insatisfação no trabalho os quais podem desmotivar o trabalhador e por conseqüência incitar o aumento do absenteísmo.

É sabido que o absenteísmo é decorrente de multicausalidade, mas a legislação existente em muitos países só abona faltas por motivo de saúde, sendo assim, os trabalhadores recorrem ao atestado médico para 
justificar suas faltas e não sofrer prejuízo em seus proventos, quando muitas das vezes as faltas não estão relacionadas a agravo à saúde.

Funcionários insatisfeitos e desmotivados são propensos a apresentar falhas na realização de suas tarefas e maior incidência de agravos à saúde, apresentando maior número de absenteísmo (Santos, 1999).

A apresentação de atestados médicos por parte dos funcionários gera um clima de desconfiança por parte das chefias imediatas quanto à sua veracidade e responsabilidade do trabalhador pelas ausências.

Silva \& Marziale (2000) reforçam que o absenteísmo pode estar diretamente relacionado às condições de trabalho. Na ótica de Lopes (1992); Anselmi (1997); Alves (1996) e Lima Júnior \& Ésther (2001), as condições de trabalho da enfermagem, principalmente no âmbito hospitalar, repercutem no grau de absenteísmo de um determinado grupo. O rodízio constante de horário, as longas jornadas de trabalho, os turnos desgastantes (vespertino, noturno, domingo e feriado), o elevado esforço físico, a multiplicidade de funções, o ritmo excessivo de trabalho, o desenvolvimento de tarefas desagradáveis, repulsivas e aterradoras podem elevar a tensão emocional que acrescidos à baixa remuneração e ao duplo vínculo empregatício, acabam gerando danos à saúde e favorecendo a ocorrência de acidentes ou até mesmo a morte prematura dos trabalhadores de enfermagem.

As condições de trabalho englobam tanto as características do próprio lugar (iluminação, aeração, presença de gases, poeiras e vapores de 
produtos químicos, fumaças, radiações e agentes biológicos), quanto os elementos relativos à atividade em si (tipo de trabalho, posição do trabalhador, ritmo e horário do trabalho), entre outros. Dependendo da intensidade e tempo de contato dos indivíduos com esses elementos podem resultar formas variadas de danos à saúde do trabalhador.

A legislação brasileira é clara quando se refere aos riscos relacionados ao trabalho, enfocando os mais diversos ambientes, ocupações e agentes de doenças e acidentes, notadamente no setor de serviços de saúde. Nesse sentido, impõe parâmetros para avaliação quantitativa ou qualitativa do risco a que os trabalhadores estão submetidos (Brasil, 2001).

Condições de trabalho inadequadas expõem os trabalhadores de enfermagem a uma multiplicidade de agentes de riscos os quais podem ser de origem física, química, biológica, ergonômica, mecânica e psicossocial (Silva, 1999). Nesses ambientes laborais, a saúde e a segurança dos trabalhadores estão ameaçadas, o que favorece o aparecimento de doenças e a ocorrência de acidentes com reflexos no absenteísmo.

As instituições de saúde são mais propensas a expor seus profissionais a problemas de saúde devido ao tipo de trabalho desenvolvido, às características do ambiente de trabalho e às atividades insalubres executadas, portanto os trabalhadores de enfermagem estão, constantemente, expostos aos riscos ergonômicos, tanto na prestação do cuidado direto ao paciente, quanto no preparo e acondicionamento de materiais, carregamento de peso excessivo, longos percursos percorridos, 
posturas penosas e deslocamentos freqüentes (Silva, 1999 e Barboza, 2001).

A exposição a agentes psicossociais também é uma constante para os profissionais da saúde. Tais agentes estão relacionados à carga afetiva e ao contato com o sofrimento dos pacientes e familiares. Atuando em situações limítrofes entre a vida e a morte, os trabalhadores enfrentam uma sensação de impotência frente às condições de terminalidade dos pacientes (Silva, 1999).

Hoga (1998) cita vários fatores que causam sobrecarga física e emocional assim como ansiedade e estresse no trabalho do enfermeiro, entre elas:

- trabalhar em situações de emergência;

- lidar com situações desconhecidas sobre as quais não se tem domínio;

- cuidar de pessoas que evoluem para o óbito;

- repetição de procedimentos;

- servir de receptáculo das raivas e/ou frustrações dos familiares;

- conviver com a morte;

- dificuldade de relacionamento interpessoal com membros da equipe;

- enfrentar tripla jornada de trabalho;

- poder dedicar pouco tempo a si mesmo;

- conflitos gerais relativos aos recursos humanos e materiais. 
Especificamente no atendimento realizado na rede básica, os profissionais de saúde sofrem ansiedade e angústia geradas pela demanda, tanto pela sua quantidade, quanto por seu conteúdo: dores, pobreza, loucura e violência (Matumoto et al., 2003). Além das agressões verbais, ultimamente, com certa freqüência os trabalhadores das unidades de saúde têm sofrido agressão física dos usuários no momento do atendimento. A clientela alega os seguintes "motivos": a demora para ser atendido, exames não solicitados, negação de atestado médico, procedimentos não realizados e solicitação de encaminhamento e internações hospitalares não concedidos.

Para Mendes (2001), o trabalho da enfermagem por si só, constitui fonte de estresse em função do sofrimento dos clientes, dos acontecimentos inesperados e da necessidade de agir com diligência.

O estresse acarreta sintomas físicos que podem ser manifestados nas mais variadas queixas.

Estudos acerca dos sintomas físicos de estresse na equipe de enfermagem, tanto em ambiente hospitalar como em unidades distritais, verificaram a presença de sintomas como: sensação de fadiga, dor de cabeça por tensão ou dor muscular, diminuição do interesse sexual, sensação de desânimo, dificuldade em conciliar o sono, tendência à sudorese e taquicardia, dor no estômago, tremores musculares, dispnéia, redução do apetite, entre outros. As autoras são enfáticas em afirmar que esses sintomas interferem negativamente na vida do funcionário e no seu trabalho, gerando freqüentes absenteísmos, que se transformam em círculos 
viciosos, pois os trabalhadores presentes se sentem sobrecarregados pela ausência dos colegas, levando-os também a não comparecer ao trabalho (Carvalho \& Lima, 2001, Pegoraro, 2002).

Essas faltas influem diretamente na quantidade e qualidade da assistência prestada aos clientes e constituem fonte de preocupação para administradores e gerentes, principalmente quando o absenteísmo é decorrente de doenças (Silva, 1999).

Embora o absenteísmo venha sendo focalizado predominantemente sob a ótica da saúde ocupacional este fenômeno inserese em um contexto mais amplo, qual seja, o da gerência de Recursos Humanos, em particular no que se refere ao dimensionamento de pessoal para a área de enfermagem transcendendo, portanto, a área da medicina do trabalho/saúde ocupacional.

Sob essa perspectiva, o absenteísmo representa uma das variáveis que interfere na organização dos serviços e no estabelecimento do quadro de recursos humanos (Echer et al., 1999).

A variável relativa às ausências foi introduzida no dimensionamento de pessoal pela Associação Americana de Hospitais / Liga Nacional do Ensino de Enfermagem pela primeira vez num estudo realizado, em 1947, e publicado em 1956. Esta investigação propõe que ao número total de funcionários definidos para o quadro de pessoal seja acrescentado um percentual de $20 \%$ de trabalhadores, no sentido de garantir a cobertura das ausências no trabalho (Gaidzinski, 1998).

Em qualquer instituição, pública ou privada, o quantitativo de 
recursos humanos necessita ser mantido em níveis adequados, com o propósito de atender à demanda de atividades que ali se desenvolvem (Bezerra, 1997).

Para Magalhães et al. (1995), o dimensionamento de recursos humanos deve ser realizado de maneira criteriosa, tanto na determinação de aspectos quantitativos, assim como nos aspectos da qualificação que cada membro da equipe deve possuir.

Dimensionar o quadro de pessoal é uma atribuição da enfermeira que, por atuar diretamente na assistência, possui competência para identificar as reais necessidades da clientela, assim como avaliar os recursos humanos disponíveis para realizá-los (Campedelli et al., 1987).

A Resolução COFEN 189/96 estabelece parâmetros para dimensionamento do quadro de profissionais de enfermagem nas instituições de saúde reafirmando que compete ao enfermeiro estabelecer o quadro qualitativo e quantitativo de profissionais necessários à prestação da assistência de enfermagem.

Esse assunto tem sido difícil e polêmico para os responsáveis pelo gerenciamento da assistência de enfermagem. Na maioria das instituições de saúde, a equipe de enfermagem representa um grande contingente de pessoal e, conseqüentemente, comporta um custo elevado na folha de pagamento sendo, portanto, a mais visada quando se pretende conter as despesas e reduzir os custos (Santos, 1992 e Gaidzinski, 1998).

Outra dificuldade apontada é a falta de uma metodologia que utilize parâmetros bem definidos em termos operacionais e de instrumentos 
que dêem conta de identificar e compreender as diferentes variáveis, entre elas o absenteísmo, envolvidas no processo de planejamento de recursos humanos. Muitas vezes, o provimento de pessoal é realizado de forma aleatória, empírica, sem argumentação sólida, não sendo capaz de evidenciar as reais necessidades e apresentar justificativas convincentes acerca dos benefícios que um quadro de pessoal adequado traz tanto para o cliente quanto para a instituição (Tranquitelli, 1999; Fugulin, 2002). Para além dos aspectos destacados por essas autoras, é importante considerar no dimensionamento de pessoal de enfermagem o modelo assistencial que será contemplado.

enfermagem perante os administradores, dando margem também à interferência de profissionais de outras áreas na determinação quantiqualitativa do quadro de pessoal de enfermagem (Campedelli et al., 1987; Gaidzinski, 1994).

Os ocupantes de cargos de direção, na maioria das vezes, utilizam-se de indicadores de produtividade como: taxa de ocupação e média de permanência para proceder ao dimensionamento de enfermagem, o que na prática nem sempre contempla as necessidades reais do trabalho vivenciado. As enfermeiras precisam demonstrar aos responsáveis da instituição os riscos a que são expostos os pacientes, quando o provimento de recursos humanos necessários para a prestação de cuidados não é realizado dentro de padrões que garantam a qualidade da assistência (Gaidzinski, 1998; Fugulin, 2002). 
Entendendo que é direito da população dispor de uma assistência à saúde qualificada, as instituições devem prover os meios e recursos para atendê-las, seja quantitativa como qualitativamente (Barboza, 2001).

A reformulação do sistema de saúde em nosso país tem se desenvolvido em um contexto de grave crise econômica. Há um descompasso gerado em função do aumento da demanda no atendimento e diminuição de recursos orçamentários. Essa conjuntura econômica reflete-se no desenvolvimento dos recursos humanos e na qualidade da assistência. Se por um lado, as instituições de saúde se propõem à implantação da qualidade em seus serviços e dependem de seus trabalhadores para alcançá-la, por outro lado, pouco têm investido no aperfeiçoamento de seus profissionais e continuamente instituem medidas de redução na contratação do pessoal (Brasil, 1993; Anselmi, 2001). Na maioria das instituições, a equipe de enfermagem é responsabilizada pelos altos custos hospitalares. Essa visão distorcida, aliada às restrições impostas pela crise econômica, tem dificultado a definição de um quadro de pessoal de enfermagem adequado à prestação da assistência dentro de padrões desejáveis (Magalhães et al., 1995).

O desafio tem sido a busca do equilíbrio que permita atender à demanda de serviços gerados pela população com melhor utilização de recursos materiais, financeiros e humanos (Anselmi, 2000).

Frente às novas exigências de gestão, os enfermeiros investidos da função gerencial devem se instrumentalizar para que sejam 
capazes de planejar, controlar, coordenar, valorizar e otimizar seus recursos humanos.

Considerando os conceitos de absenteísmo abordados anteriormente, muitos fazem referência a qualquer tipo de ausência do indivíduo no trabalho. Entretanto, quando se trata de dimensionar o quadro de pessoal para o desenvolvimento das atividades em determinado serviço de enfermagem, é necessário tomá-lo de forma distinta, ou seja, existem ausências que podem ser previstas e, neste sentido, a cobertura poderá ser realizada de forma planejada. As chamadas ausências não previstas repercutem na organização cotidiana do trabalho e, portanto, exigem tratamento e estratégias de planejamento diferenciadas.

Recorremos a Gaidzinski $(1994,1998)$ que, nestes últimos anos, tem se dedicado ao estudo do dimensionamento de pessoal de enfermagem para área hospitalar, aprofundando conhecimentos nas questões das ausências.

A referida autora distingue as ausências em previstas e não previstas, considerando estas últimas como absenteísmo. As ausências previstas são aquelas de direito do trabalhador e planejadas na escala como as férias e as folgas por descanso semanal remunerado e feriados. As ausências não previstas são as que efetivamente caracterizam o absenteísmo, pelo seu caráter imprevisível, entre elas: faltas abonadas e injustificadas; licenças médicas para tratamento de saúde, maternidade, paternidade e acidente de trabalho; outras licenças amparadas por lei e/ou de direito do servidor (nojo, gala, congressos). 
Devido à peculiaridade das instituições de saúde, nas quais o atendimento às necessidades dos clientes não pode ser adiado, as estratégias administrativas freqüentemente adotadas para enfrentar o problema do absenteísmo têm sido o pagamento de hora extra e solicitação de prorrogação de horário.

Essas providências foram censuradas por Santos (1999), ao dizer que o funcionário que trabalha além do seu turno sentirá uma sobrecarga de trabalho, grande desgaste físico e psíquico, ansiedade, estresse e insatisfação.

Sobre o assunto Fischer (1984) comenta que o funcionário que faz hora extra vislumbra ganhos adicionais, mas em contrapartida imprime a si um ritmo intenso de trabalho, deixando de usufruir as indispensáveis horas de descanso e lazer.

Frente às considerações apresentadas, entendemos que o absenteísmo constitui uma problemática da gerência de Recursos Humanos. Nesse sentido, tornam-se necessários estudos que reconheçam este fenômeno em sua dimensão quantitativa, mensurando-o através de coeficiente específico; e ainda que evidenciem os tipos e respectiva freqüência das ausências não previstas com vistas à implementação de políticas institucionais que possibilitem monitorar e prevenir sua ocorrência.

\subsection{Absenteísmo: propostas de mensuração}

Uma das formas de conhecer a magnitude do absenteísmo no âmbito organizacional é mensurá-lo através do Índice de Absenteísmo (IA). 
Este é um indicador que reflete a porcentagem de tempo (dias/horas) não trabalhado devido às ausências em relação ao volume de atividades planejadas (Chiavenato, 1997).

Gaidzinski (1991, 1998), para analisar as ausências da equipe de enfermagem, propõe equações específicas para ausências previstas (folgas semanais, feriados e férias).

Pavani (2000) esclarece que a Organização Internacional do Trabalho recomenda a exclusão de férias e folgas para o cálculo do Índice de Absenteísmo, por serem ausências previstas. Assim essa autora, com base nos estudos de Gaidzinski, propõe uma equação abaixo apresentada que contempla todos os tipos de ausências não previstas como: faltas; licença médica; licença-maternidade; licença por acidente; licença INSS; outros tipos de licenças e suspensões.

$$
A_{k, i}=\frac{N_{k, i b}}{D \cdot q_{k}-\Sigma_{i} N_{k, i}} \cdot 100 \quad \text { em que: }
$$

- $\mathrm{k}$ = índice que indica cada categoria profissional (enfermeiro, técnico e auxiliar de enfermagem);

- i = índice que indica cada tipo de ausência não prevista (faltas e licenças);

- $\mathrm{N}_{\mathrm{k}, \mathrm{i}}=$ quantidade de dias/ano de ausências não prevista $\mathrm{i}$ cometidas por todos os trabalhadores de uma dada categoria profissional k;

- $\mathrm{D}=$ quantidade de dias trabalhados no ano pela unidade;

- $\mathrm{q}_{\mathrm{k}}=$ quantidade de trabalhadores da categoria profissional $\mathrm{k}$ 
da unidade;

- $\Sigma_{\mathrm{i}} \mathrm{N}_{\mathrm{k}, \mathrm{i}}=$ soma dos dias/ano de todas as ausências não previstas, cometidas pelos $q_{k}$ trabalhadores da unidade.

Nos processos de dimensionamento de pessoal de enfermagem é imprescindível conhecer o índice de absenteísmo para que seja viável estabelecer o percentual de pessoal necessário para a cobertura dessas ausências, sob a denominação de Índice de Segurança Técnica (IST).

$\mathrm{Na}$ revisão da literatura, encontramos diversos valores propostos para o Índice de Segurança Técnica.

A Associação Americana de Hospitais e a Liga Nacional de Educação em Enfermagem (1956) estipulam 20\% para a cobertura das ausências da equipe de enfermagem.

Alcalá et al. (1982) ao desenvolverem um estudo sobre dimensionamento de pessoal junto à Superintendência Médica Hospitalar de Urgência no Município de São Paulo, estabeleceram 30\% para o IST.

Campedelli et al. (1987) acrescentaram para a cobertura das ausências considerando as folgas, férias, faltas e licenças o percentual de 33,3\% para a unidade de pediatria e 37\% para a unidade de clínica médica, ambas enfocadas no estudo realizado.

A Secretaria de Estado da Saúde, através do Centro de Apoio ao Desenvolvimento de Assistência Integral à Saúde (CADAIS) / Grupo Tarefa de Pessoal de Enfermagem, num estudo realizado para dimensionar o pessoal de enfermagem, determinaram o índice de 33\% para a cobertura 
de férias, folgas e licenças (Ueti et al., 1991).

O Conselho Federal de Enfermagem (COFEN) estabeleceu através da Resolução n. 189, de 16 de março de 1996, que o IST não deveria ser inferior a $30 \%$.

Pelos trabalhos apresentados no Brasil, há valores bastante variados para esse acréscimo, geralmente obtidos de forma empírica, ocasionando erros e dúvidas na aplicação das fórmulas adotadas para dimensionar o pessoal de enfermagem (Gaidzinski, 1998).

O absenteísmo pode também ser avaliado através da verificação do número médio de dias de ausências não previstas em um determinado período.

Frente à revisão da literatura apresentada que evidenciou a escassez de estudos sobre o absenteísmo na rede básica de saúde, à experiência profissional na gerência de serviços de saúde, em particular, nas questões relativas aos recursos humanos e ainda, à vivência cotidiana em uma Unidade Básica e Distrital de Saúde (UBDS), na qual nos deparamos permanentemente com as ausências dos trabalhadores de enfermagem no serviço e as repercussões que estas trazem na assistência à clientela atendida, algumas questões emergiram, entre elas: qual o índice de absenteísmo dos trabalhadores de enfermagem que atuam numa UBDS? Quais os tipos de ausências não previstas predominantes neste grupo de trabalhadores de enfermagem?

As respostas a tais indagações possibilitarão conhecer melhor o fenômeno em questão, absenteísmo dos trabalhadores de enfermagem, 
em um espaço particular de atenção, a rede básica de saúde, com vistas a instrumentalizar a gerência local no que se refere ao acompanhamento/monitoramento das ausências não previstas. 


\section{OBJETIVOS}


- Mensurar o absenteísmo dos trabalhadores de enfermagem de uma Unidade Básica e Distrital de Saúde no município de Ribeirão Preto, no período de agosto de 1998 a julho de 2002.

- Descrever a distribuição dos tipos de ausências não previstas apresentadas por este grupo de trabalhadores. 
4. METODOLOGIA 


\subsection{Tipo de estudo}

Esta investigação foi desenvolvida na abordagem quantitativa de forma retrospectiva, através de um estudo exploratório e descritivo.

O método quantitativo é um processo formal, objetivo, sistemático que, por meio do uso de dados numéricos, fornece informações acerca do mundo. É utilizado para descrever, testar relações e determinar causas (Koizumi, 1992).

O caráter descritivo, segundo Polit \& Hungler (1995), tem como propósito explorar, descrever e observar aspectos de uma situação; busca analisar um fenômeno de interesse, procurando descrevê-lo, classificá-lo e interpretá-lo.

\subsection{Local de estudo}

A pesquisa foi realizada na cidade de Ribeirão Preto, estado de São Paulo e, portanto considera-se importante a abordagem de algumas características do município e sua rede de serviços de saúde.

As informações apresentadas a seguir foram extraídas do Plano de Saúde da Secretaria Municipal de Saúde (Ribeirão Preto, 2001).

Localizado a 320 km da capital, o referido município pertence à região nordeste do estado de São Paulo. Fundado em 19 de junho de 1856 por movimentos migratórios que tinham como interesse a produção do café. A qualidade dos solos e o clima fazem com que essa região seja ainda hoje 
uma das principais regiões agrícolas do estado de São Paulo e do país, destacando-se os produtos: cana-de-açúcar, laranja, soja e amendoim. A produção de açúcar e álcool é elevada; somada às cidades circunvizinhas existe um total de 21 usinas que dão emprego a 8.000 trabalhadores. Além das usinas, há várias indústrias alimentícias de ração e de fertilizantes bem como soja e amendoim que formam o complexo agroindustrial da região. Merecem destaque, também, outros setores industriais como o de equipamentos médico-odontológicos e farmacêuticos.

Apresenta baixos índices de poluição atmosférica, sendo as principais fontes poluidoras, a fuligem, os gases emanados da queima da cana-de-açúcar e o monóxido de carbono proveniente de veículos motores.

A população estimada pelo IBGE em 2000 era de 505.012 habitantes dentro de uma área de $651 \mathrm{~km}^{2}$, sendo que a maioria dessa população está concentrada na zona urbana (502.333 moradores) e somente 2.679 habitantes na zona rural. Segundo Pinto (1999), esse quadro de alta concentração populacional em áreas urbanas nas grandes cidades é resultante de um movimento histórico em todo o país em que as pessoas em busca de melhores condições de vida e oportunidades de emprego deixam o campo e rumam para as cidades. Esse fato tem ocorrido também em Ribeirão Preto, que vem apresentando elevada taxa de crescimento demográfico principalmente nas últimas décadas, sendo sua taxa de urbanização no ano de 2000 , de 99,47\% devido ao dinamismo econômico e à qualidade de vida dessa cidade.

A estrutura etária da população concentra-se entre 15 e 64 
anos e a pirâmide populacional indica a tendência de aumento da expectativa de vida e diminuição da natalidade. Os maiores coeficientes de mortalidade estão nas doenças cardiovasculares, neoplasias e causas externas, sendo as últimas fruto da violência urbana, acidentes de trânsito, homicídios e as relacionadas ao uso, abuso e tráfico de drogas.

A situação epidemiológica referente à saúde do trabalhador é desconhecida, pois no momento, os dados relativos aos acidentes de trabalho e doenças ocupacionais não são analisados.

Possui um dos principais centros universitários e de pesquisa do estado e do País na área de saúde com cursos de medicina, enfermagem, odontologia, psicologia, fisioterapia, biomedicina, farmacologia e medicina veterinária. Destaca-se uma universidade pública de grande porte (Universidade de São Paulo), cujo setor de pesquisa corresponde a 4\% dos trabalhos acadêmicos produzidos no Brasil. Várias instituições universitárias privadas atuam também na formação profissional, nas áreas de direito, engenharia, administração e outras.

\subsubsection{Organização dos serviços de saúde no município de Ribeirão Preto-SP}

Ribeirão Preto é conhecida nacionalmente como importante centro de recursos de saúde. Destaca-se no ranking nacional na proporção médico por habitante, sendo um para cada 160 habitantes, totalizando três mil médicos.

O município é sede da Diretoria Regional de Saúde - DIR XVIII 
que abrange 25 municípios, passando a ser referência regional, até mesmo para outros estados, em relação ao atendimento em saúde.

A rede municipal de saúde está estruturada em cinco Unidades Básicas e Distritais de Saúde (UBDS), 27 Unidades Básicas de Saúde (UBSs), um Ambulatório Regional de Especialidades (NGA-59), um Ambulatório Geral de Especialidades Pediátricas (PAM II), um Núcleo de Atenção Psicossocial (NAPS), um Núcleo de Atenção Psicossocial para Farmacodependentes (NAPSF) e um Ambulatório Regional de Saúde Mental.

A rede hospitalar é composta por 13 hospitais que totalizam 1.746 leitos disponíveis, sendo 1.411 conveniados ao Sistema Único de Saúde (Ribeirão Preto, 2001).

A assistência à saúde está estruturada segundo o conceito de bases territoriais com áreas e populações definidas a partir de aspectos geográficos, econômicos e sociais, sendo essas regiões denominadas Distritos de Saúde.

Cada Distrito de Saúde compreende um complexo assistencial e conta com uma Unidade Básica e Distrital de Saúde (UBDS) e várias Unidades Básicas de Saúde (UBS).

Atualmente o município possui cinco distritos sanitários localizados nas seguintes regiões:

- Norte - distrito do Simioni, composto por uma UBDS e seis UBSs.

- Sul - distrito de Vila Virgínia,composto por uma UBDS e três 
UBSs.

- Leste - distrito do Castelo Branco, composto por uma UBDS e seis UBSs.

- Oeste - distrito do Sumarezinho, composto por uma UBDS, sete UBSs e dois centros de saúde.

- Central - distrito central, composto por uma UBDS, três UBSs e um centro de saúde.

Essa distribuição geográfica tem com propósito oferecer aos munícipes um atendimento básico e de pronto atendimento em emergência próximo à sua residência.

A UBS é uma unidade de saúde que tem como finalidade prestar atendimento nas especialidades médicas básicas (pediatria, clínica médica, ginecologia e obstetrícia), odontológicas e de enfermagem.

A UBDS oferece retaguarda às UBS do distrito e além dos serviços descritos, oferece também atendimento em nível secundário nas especialidades de cardiologia, dermatologia, endocrinologia, fonoaudiologia, psicologia, urologia, entre outros; e todas as ações de Vigilância Epidemiológica e urgência nas 24 horas.

Todas as unidades possuem retaguarda de laboratório clínico, ultra-sonografia, radiologia simples e eletrocardiografia. Nas unidades distritais e ambulatórios de especialidades, são solicitados exames que requerem tecnologia mais avançada através dos serviços contratados e/ou conveniados.

Portanto, as unidades de saúde (UBS e UBDS) são 
responsáveis pelo atendimento em nível primário à população e são consideradas como porta de entrada do sistema de saúde.

A rede secundária de atenção compõe-se do Núcleo de Gestão Assistencial (NGA-59), Ambulatório Regional de Saúde Mental, NAPS -1 e NAPS - F e no PAM II e do Hospital das Clínicas da Faculdade de Medicina de Ribeirão Preto-USP.

O atendimento a nível terciário se dá por meio de convênios com hospitais filantrópicos e em parceria com HCFMRP-USP.

A rede municipal de saúde, constituída de serviços próprios e conveniados/contratados, apresenta um fluxo de atendimento hierarquizado e regionalizado; os atendimentos não disponíveis em nível ambulatorial são encaminhados para os serviços hospitalares através dos instrumentos de referência e contra-referência e de uma central única de regulação médica para o atendimento de urgência/emergência, implantada em 2000.

Além da rede pública, a população conta com o sistema privado principalmente pela medicina de grupo (Unimed, São Francisco, Amico) cujos convênios são feitos diretamente pelo cliente através de plano individual ou por empresa.

Após a implantação do SUS e a assinatura do convênio de municipalização da saúde em 1987, o município de Ribeirão Preto foi assumindo, gradativamente, a responsabilidade pela gestão de atenção à saúde de seus munícipes e, em maio de 1998, com base na NOB-SUS/96 foi habilitado à condição de Gestão Plena do Sistema.

Esta Norma Operacional Básica define o financiamento do 
setor saúde e consolida o pleno exercício por parte do poder público municipal. Dessa forma, o município é responsável pela gestão local da saúde e o gerenciamento de sua própria rede de serviços.

Recentemente o município implantou o Programa de Saúde da Família (PSF) cujo alvo é a família e seu território. O PSF é uma estratégia para organização dos serviços de saúde e vem para reforçar os princípios do SUS. Apresenta caráter interdisciplinar, com suas equipes instaladas nas UBSs, possibilita a universalidade da assistência humanizada e equânime, através dos vínculos que estabelece com as famílias.

A equipe do PSF é responsável pela saúde da população adscrita à sua área de atuação de forma permanente, atendendo a casos de menor complexidade tecnológica/industrial e encaminhando os demais, quando necessário aos especialistas. As ações de saúde voltadas aos indivíduos devem se inserir no contexto estrutural da família e comunidade.

\subsubsection{A Unidade Básica e Distrital de Saúde "Dr. Ítalo Baruffi"- Castelo Branco}
A Unidade Básica e Distrital de Saúde selecionada para estudo, local onde o pesquisador desenvolve suas atividades profissionais, localiza-se na região leste do município de Ribeirão Preto e dá retaguarda de atendimento a seis Unidades Básicas de Saúde.

A população da área de abrangência dessa distrital é de 93.326 habitantes (Ribeirão Preto, 2001). A distrital dá atendimento à população de forma ininterrupta e, para isso, conta com um quadro de 
recursos humanos de enfermagem totalizando 47 servidores, sendo: 11 enfermeiros; quatro técnicos e 32 auxiliares de enfermagem.

\subsubsection{A questão do absenteísmo na Secretaria Municipal de Saúde de Ribeirão Preto - SP}

A contratação dos funcionários na SMS é feita através de concurso público.

O contrato de trabalho para enfermeiros é de 20 horas semanais, podendo se ampliar até 40 horas, e para, os profissionais de nível médio (técnico e auxiliar de enfermagem) é de 40 horas semanais que poderá ser reduzido em até 20 horas. Em ambos os casos de alteração de jornada semanal de trabalho, há necessidade de manifestação de interesse por parte dos servidores, assim como do deferimento da SMS.

O Estatuto dos Funcionários Municipais de Ribeirão Preto (Colla et al., 1997) e pesquisa realizada on-line através do site http:॥www.saude.ribeirãopreto.sp.gov.br definem os tipos de afastamentos permitidos aos servidores municipais, incluindo-se aqui os da SMS.

Considerando que o presente estudo trata especificamente do absenteísmo, ausências não previstas, selecionamos dentre o conjunto de tipos de afastamento estabelecidos pelo Estatuto, aqueles que serão objeto de mensuração, tomando como critério aquelas ausências para as quais não é possível para a gerência local, no momento de planejamento anual das atividades, prever antecipadamente a sua ocorrência. Desse modo, foram estudados os seguintes tipos de ausência: 
- Falta abonada - É a falta a que o servidor tem direito e poderá usufruir uma por mês e até 11 no ano, sem prejuízo de seus vencimentos. Para tanto o funcionário precisa formalizar o pedido à chefia imediata dentro de cinco dias úteis anteriores à data de sua concessão. Somente estão excluídos desse direito os funcionários em regime de plantão.

- Falta injustificada - É a falta que o servidor apresenta sem justificativa para sua ausência ao trabalho e, se apresenta, o motivo não é aceito pela chefia.

- Licença à gestante - É o período de afastamento concedido à mulher para o parto e puerpério. A licença é de até quatro meses consecutivos com remuneração para a gestante, após o oitavo mês de gestação. São contemplados também os casos de adoção e guarda judicial de crianças de até sete anos.

- Licença por acidente de trabalho - É a licença concedida ao funcionário que sofre acidente no trabalho ou trajeto casa-trabalho, trabalho-casa, com indicação de afastamento.

- Licença-prêmio - É a licença de três meses, remunerada, que o servidor tem direito após completar cinco anos de efetivo exercício. Trata-se de um prêmio concedido a cada período de cinco anos, em razão do serviço prestado à administração pública municipal. Desde que o funcionário não apresente: 10 faltas injustificadas, e/ou 180 dias de licença de saúde, e/ou 60 dias de licença para cuidar de pessoas da família.

- Licença para tratamento de saúde - É aquela comprovada 
por atestado médico, concedida quando o servidor estiver impossibilitado física ou psicologicamente de exercer suas funções.

- Licença gala - É a licença concedida ao servidor por ocasião de seu casamento, sendo de oito dias consecutivos.

- Licença nojo - É a licença concedida ao servidor por ocasião de falecimento de membros da família até o $2^{\circ}$ grau civil ou do cônjuge, sendo de oito dias consecutivos.

- Licença por motivo de doenças em pessoa da família - É a licença concedida ao funcionário que necessitar faltar ao trabalho para cuidar de pessoas da família que se encontram doentes. Devendo ser provada a doença com atestado médico e a indispensabilidade da assistência pessoal. Essa licença será com remuneração integral, se for por um período de três meses. De três meses a dois anos o recebimento será de 2/3 dos seus vencimentos.

- Suspensão - É o impedimento ao servidor de prestar serviço em decorrência de algum tipo de repreensão e nessas condições não recebe remuneração relativa aos dias parados.

- Licença-paternidade - É a licença concedida ao servidor por ocasião de nascimento de filho, sendo de cinco dias consecutivos.

- Licença congresso - É a licença concedida ao servidor para participar de Congressos, devendo manter um intervalo mínimo de 365 dias entre um evento e outro; é permitido até cinco dias consecutivos. 


\subsection{População}

A população foi constituída pelos trabalhadores de enfermagem (enfermeiro, técnico e auxiliar de enfermagem) que no período de agosto de 1998 a julho de 2002 encontravam-se alocados na UBDS selecionada para a investigação.

\subsection{Processo de pesquisa: instrumento, coleta e análise dos dados}

Para a coleta dos dados foi utilizado um instrumento adaptado daquele desenvolvido por Fugulin (2002) que contempla o levantamento das ausências não previstas nas suas diferentes modalidades (Anexo 1).

A planilha é constituída pelos campos descritos abaixo:

- Identificação da unidade: inclui o nome da unidade e o período da coleta de dados;

- Categoria profissional: nesse item estão relacionadas as categorias do pessoal de enfermagem: enfermeiro, técnico e auxiliar de enfermagem.

- Quantidade média de pessoal: refere-se ao número efetivo de elementos por categoria profissional, durante o período estudado.

- Ausências não previstas: destina-se ao levantamento das ausências não previstas devido a:

- Faltas: registro mensal dos dias de faltas (abonadas e injustificadas), por categoria profissional. 
- Licenças: registro mensal dos dias de licença de saúde, acidente de trabalho, gestante, doença em familiar, prêmio e outras licenças (nojo, paternidade e congresso).

- Suspensões: registro mensal dos dias de afastamento devido às normas disciplinares, por categoria profissional.

Os critérios definidos para fins do levantamento das ausências não previstas encontram-se descritos no anexo 2 .

Após autorização do Secretário da Saúde, fizemos contato com a Divisão de Gerenciamento de Pessoal da Secretaria Municipal da Saúde. Foi-nos fornecida a listagem dos servidores de enfermagem que prestaram serviços na UBDS no período de agosto de 1998 a julho de 2002. Os dados foram coletados retrospectivamente através de um programa "Sistema on line de Administração de Pessoal". Este programa possui registro individual de todos os tipos de afastamento do servidor.

Essas informações foram levantadas manualmente, registrando-se o quantitativo de afastamentos não previstos em dias anotando no instrumento citado, visando a maior facilidade na tabulação dos dados de ausências da equipe de enfermagem.

A mensuração do absenteísmo foi efetuada por meio da equação proposta por Pavani (2000) e descrita abaixo:

$$
A_{k, i}=\frac{N_{k, i}}{D \cdot q_{k}-\Sigma_{i} N_{k, i}} \cdot 100 \quad \text { em que: }
$$

- $\mathrm{k}$ = índice que indica cada categoria profissional (enfermeiro, 
técnico e auxiliar de enfermagem);

- i = índice que indica cada tipo de ausência não prevista (faltas e licenças);

- $\mathrm{N}_{\mathrm{k}, \mathrm{i}}=$ quantidade de dias/ano de ausência não prevista $\mathrm{i}$ cometidas por todos os trabalhadores de uma dada categoria profissional k;

- $\mathrm{D}$ = quantidade de dias trabalhados no ano pela unidade;

- $\mathrm{q}_{\mathrm{k}}=$ quantidade de trabalhadores da categoria profissional $\mathrm{k}$ da unidade;

- $\Sigma_{\mathrm{i}} \mathrm{N}_{\mathrm{k}, \mathrm{i}}=$ soma dos dias/ano de todas as ausências não previstas cometidas pelos $q_{k}$ trabalhadores da unidade.

O absenteísmo médio da unidade por categoria profissional é obtido pela soma de todas as ausências não previstas cometidas por aquela categoria profissional e pode ser calculado pela equação:

$$
A_{k, i}=\frac{\Sigma N_{k, i}}{D \cdot q_{k}-\Sigma_{i} N_{k, i}} \cdot 100
$$

cujos componentes já foram descritos anteriormente.

Para descrição dos dados referentes aos tipos de ausências, foi utilizada estatística descritiva e os resultados apresentados sob a forma de tabelas e figuras.

\subsection{Procedimentos éticos}

Esta investigação está incluída na categoria de pesquisa sem 
risco, conforme classificação utilizada para pesquisa em saúde, pelo Conselho Nacional de Saúde. No entanto, o pesquisador se compromete a utilizar as informações contidas na pesquisa, preservando o anonimato para que não haja repercussão profissional para os funcionários envolvidos na investigação.

De acordo com as normas estabelecidas para o desenvolvimento de pesquisa, o projeto foi encaminhado ao Secretário Municipal de Saúde de Ribeirão Preto, obtendo permissão, por escrito em 30 de agosto de 2002 (Anexo 2). A seguir, encaminhamos o projeto de pesquisa para apreciação e aprovação do Comitê de Ética da Escola de Enfermagem de Ribeirão Preto da Universidade de São Paulo. O projeto foi aprovado em 19 de setembro de 2002. (Anexo 3). 
5. RESULTADOS E DISCUSSÃO 
Os resultados apresentados e respectiva análise contemplam dois aspectos, a saber: o Índice de Absenteísmo (IA) verificado na Distrital de Saúde estudada para o grupo de trabalhadores de enfermagem (enfermeiro, técnico de enfermagem e auxiliar de enfermagem) e a distribuição dos tipos de ausência.

\section{1 Índice de Absenteísmo da equipe de enfermagem}

Para análise do índice de absenteísmo, buscamos, em um primeiro momento, conhecer a quantidade média de pessoal de enfermagem existente na unidade em cada período de estudo. Os dados apresentados na Tabela 1 estão dispostos segundo o período estudado na seguinte conformidade: $1^{\circ}$ período - agosto/1998 a julho/1999; $2^{\circ}$ período agosto/1999 a julho/2000; 30 período - agosto/2000 a julho/2001; 4 período - agosto/2001 a julho/2002. Observa-se que à semelhança do que ocorre no país em relação à distribuição da força de trabalho em enfermagem, a unidade em questão apresenta um maior contingente de auxiliares de enfermagem, seguido de enfermeiros e um quantitativo reduzido de técnicos de enfermagem. Durante o período estudado, a unidade contou com uma média percentual de $20 \%$ de enfermeiros, $6,62 \%$ de técnicos e $73 \%$ de auxiliares de enfermagem. Em fevereiro de 2003, a distribuição dos trabalhadores de enfermagem no país era a seguinte: $63,1 \%$ de auxiliares de enfermagem; $18,8 \%$ de técnicos de enfermagem; $13,4 \%$ de enfermeiros e 
$4,7 \%$ de atendentes de enfermagem $\left(\right.$ COFEN,2003) ${ }^{1}$.

Em pesquisa realizada_on line em abril/2003, acerca das $\underline{\text { categorias cadastradas no Conselho Federal de Enfermagem, encontramos }}$ no estado de São Paulo a seguinte distribuição: $12,5 \%$ de enfermeiros, $12{ }_{2} 5 \%$ de técnicos, $73,5 \%$ de auxiliares e atendentes de enfermagem, $1,5 \%$. $\underline{\text { Tomando o primeiro período como base (100), verifica-se que }}$ no último período de estudo, houve um incremento percentual no número de enfermeiros e técnicos._É importante ressaltar que ao longo desse período, o quadro de recursos humanos da Secretaria Municipal da Saúde como um todo foi minimizado em decorrência de óbitos, aposentadorias, exonerações e demissões, sem que houvesse reposição de vagas. Assim, a ampliação de postos de trabalho para os enfermeiros se deu em virtude de recebimento de servidores que se encontravam em funções administrativas e em outras secretarias. Quanto aos técnicos, houve substituição de uma das vagas existentes por auxiliares de enfermagem.

Quanto aos auxiliares de enfermagem, _observa-se uma redução, em razão de não ter ocorrido reposição dos postos vacantes. Portanto, ao final do período estudado, agosto de 2002, a unidade em questão apresentava um quadro de pessoal de enfermagem $11 \%$ inferior, o que corresponde a aproximadamente seis trabalhadores. Devemos salientar que, em 22 de setembro de 1999, o atendimento de remoção externa a pacientes que era desenvolvido pelos funcionários de nível médio passou a ser realizado por firma terceirizada pela Secretaria Municipal de Saúde,

\footnotetext{
${ }^{1}$ Informações extraídas do site: http://www.corensp.org.br/conselho/sistema/cadastral.html.
} 
sendo assim, esse grupo de trabalhadores foi incorporado na escala diária da unidade.

Conforme já citado, a contratação de servidores na Secretaria Municipal de Saúde se dá após a realização de concurso público. Embora o último processo seletivo para a enfermagem tenha acontecido em janeiro de 2002, até o momento, não foram efetuadas novas admissões para este grupo de trabalhadores. As últimas admissões para o cargo de enfermeiro aconteceram em 23/06/1998 e para o nível médio, em 03/02/1998, decorrentes do processo seletivo realizado em dezembro de 1993, portanto, em período anterior ao investigado.

Outro aspecto a ser focalizado diz respeito à ampliação da rede municipal de saúde. De 1998 para maio de 2003, houve ampliação de duas Unidades Básicas de Saúde, um Centro de Referência para tratamento de DST/AIDS e um Núcleo de Saúde da Família. Como ao longo desse período não ocorreram novas contratações de trabalhadores para a rede, o crescimento do número desses serviços imprimiu_a necessidade de realocação dos profissionais de enfermagem para prestar atendimento à clientela (Ribeirão Preto, maio, 2003).

Uma das estratégias adotada pela SMS e utilizada na UBDS, em estudo para garantir a cobertura das ausências, tem sido a convocação de servidores para prestação de trabalho fora do horário normal (horas extras).

As gerências das unidades de saúde solicitam, mensalmente, à Secretaria Municipal de Saúde autorização para convocar funcionários para 
realização de horas extras. Cabe à chefia de cada departamento (médico, odontológico e de enfermagem) analisar e liberar o pedido de acordo com a disponibilidade de verba.

O trabalho extraordinário (hora extra) é considerado aquele executado além da jornada habitual. A este corresponde uma gratificação monetária no sentido de compensar o desgaste do servidor ${ }^{\star}$.

Quando o montante de recursos financeiros disponibilizados para pagamento das horas extras estiver esgotado, a cobertura das ausências é feita pelos funcionários que se disponibilizarem a trabalhar, e estes serão recompensados através de folgas.

Tabela 1. Quantitativo médio de pessoal de enfermagem e respectivo incremento (\%), segundo categoria profissional em uma UBDS. Ribeirão Preto, agosto/1998 a julho/2002.

Excluído: .

PERÍODO

\begin{tabular}{|c|c|c|c|c|c|c|c|c|c|}
\hline \multirow{2}{*}{$\begin{array}{c}\text { Categoria } \\
\text { Profissional }\end{array}$} & \multicolumn{2}{|c|}{$\underline{1}^{\circ}\left(\mathrm{N}_{0}\right)$} & \multicolumn{2}{|c|}{$\underline{2}^{\circ}$} & \multicolumn{2}{|c|}{$\underline{3^{\circ}}$} & \multicolumn{2}{|c|}{$4^{\circ}(\mathrm{N})$} & \multirow{2}{*}{$\frac{\text { Incremen }}{\text { to }(\%)^{*}}$} \\
\hline & $\mathbf{N}^{\circ}$ & $\%$ & $\mathbf{N}^{\circ}$ & $\%$ & $\mathbf{N}^{\circ}$ & $\%$ & $\mathrm{~N}^{\circ}$ & $\%$ & \\
\hline Enfermeiro & 9,25 & 17,56 & 10 & 20,10 & 10,16 & 21,17 & 10 & 21,32 & 8,1 \\
\hline Técnico & 3 & 5,70 & 3 & 6,03 & 3 & 6,25 & 4 & 8,53 & 33,3 \\
\hline Auxiliar & 40,42 & 76,74 & 36,75 & 73,87 & 34,83 & 72,58 & 32,91 & 70,15 & $-18,57$ \\
\hline TOTAL & 52,67 & 100 & 49,75 & 100 & 47,99 & 100 & 46,91 & 100 & $-10,94$ \\
\hline
\end{tabular}

Formatado

* Incremento percentual tomando o $1^{0}$ período como base, ou seja, $100 \bullet \frac{N-N_{0}}{N 0}$

.Outra informação relevante para o cálculo do Índice de

Excluído:

II Absenteísmo (IA) diz respeito à identificação da quantidade de ausências

Nos casos de trabalho extraordinário há um acréscimo no valor hora/trabalho de 50 a 100\%. Quando este trabalho ocorrer no horário noturno (22 às 6 horas), haverá um adicional de $20 \%$ sobre a hora normal. 
não previstas, em dias, ocorridas para cada categoria profissional (Tabela 2).

Do total de dias de ausências não previstas encontrado, a categoria auxiliar de enfermagem responde pelo maior número, 3.377 (75,6\%). Em seguida, têm-se os enfermeiros com 733 dias $(16,4 \%)$ e com o menor número de ausências, 354 dias (8\%), os técnicos de enfermagem.

Outros estudos, com trabalhadores de enfermagem, também verificaram elevado número de ausências para o profissional auxiliar. Silva (1999), em um hospital universitário do interior do Paraná, identificou para auxiliares de enfermagem, $82,4 \%$ de afastamentos e para enfermeiros, 17,6\%. Farias (2003) encontrou em uma seção de Pronto-Socorro especializado em afecções cardiovasculares, durante o período de um ano, um total de 557 dias de ausências, sendo 515 dias de ausências (92,5\%) para auxiliares e de 42 dias (7,5\%) para enfermeiros. Barboza (2003), em um hospital geral de grande porte, no interior paulista em 1999, encontrou $82,3 \%$ de afastamentos para os auxiliares de enfermagem.

$\mathrm{Na}$ análise por período, observa-se que o auxiliar, seguido do enfermeiro, foram as categorias que mais se ausentaram, exceto no $2^{\circ}$ período em que os técnicos superaram os enfermeiros com 195 dias (16,7\%) de ausências. 
Tabela 2. Distribuição das ausências não previstas (em dias), segundo categoria profissional e período em uma UBDS. Ribeirão Preto, agosto/1998 a julho/2002.

\begin{tabular}{ccccccccccc}
\hline & \multicolumn{10}{c}{ PERÍODO } \\
\cline { 2 - 12 } $\begin{array}{c}\text { Categoria } \\
\text { Profissional }\end{array}$ & \multicolumn{1}{c}{$\mathbf{1}^{\mathbf{0}}$} & \multicolumn{10}{c}{$\mathbf{2}^{\mathbf{0}}$} & \multicolumn{2}{c}{$\mathbf{3}^{\mathbf{0}}$} & $\mathbf{4}^{\mathbf{0}}$ & \multicolumn{2}{c}{ TOTAL } \\
\cline { 2 - 12 } & $\mathbf{N}$ & $\mathbf{\%}$ & $\mathbf{N}^{\mathbf{0}}$ & $\mathbf{\%}$ & $\mathbf{N}^{\mathbf{0}}$ & $\mathbf{\%}$ & $\mathbf{N}^{\mathbf{0}}$ & $\mathbf{\%}$ & $\mathbf{N}^{\mathbf{0}}$ & $\mathbf{\%}$ \\
\hline Enfermeiro & 196 & 17,3 & 145 & 12,5 & 137 & 14,5 & 255 & 21 & 733 & 16,4 \\
Técnico & 7 & 0,6 & 195 & 16,7 & 31 & 3,3 & 121 & 9,9 & 354 & 8 \\
Auxiliar & 933 & 82,1 & 825 & 70,8 & 778 & 82,2 & 841 & 69,1 & 3.377 & 75,6 \\
\hline TOTAL & $\mathbf{1 . 1 3 6}$ & $\mathbf{1 0 0}$ & $\mathbf{1 . 1 6 5}$ & $\mathbf{1 0 0}$ & $\mathbf{9 4 6}$ & $\mathbf{1 0 0}$ & $\mathbf{1 . 2 1 7}$ & $\mathbf{1 0 0}$ & $\mathbf{4 . 4 6 4}$ & $\mathbf{1 0 0}$ \\
\hline
\end{tabular}

A partir do número médio de dias de ausências não previstas para as três categorias de trabalhadores em cada período de estudo (1.116) e o número médio de pessoal nos quatro períodos $(49,3)$, é possível estabelecer a quantidade média de dias de ausências não previstas em cada período para cada trabalhador, qual seja, 23 dias.

Esses resultados apresentam-se mais elevados que aqueles encontrados por Akyeampong apud Larocque (1996), no qual a média anual de dias de ausência foi de 14,3 dias e do estudo de Larocque (1996), de 10,3 dias.

Com base nos dados apresentados até o momento, foi calculado o índice de absenteísmo, que será apresentado nas tabelas que se seguem.

O índice de absenteísmo expressa a percentagem de tempo não trabalhado em decorrência das ausências, em relação ao volume de atividade esperada ou planejada. Deve-se estabelecer o período que será considerado: semana, mês ou ano (Chiavenato, 1997). 
Um índice expressa situações multidimensionais à medida que incorpora em uma única medida diferentes aspectos de um evento; assim, coloca-se como a expressão de um evento sob a forma de freqüência relativa. "Na preparação de um índice, é colocado no numerador o número de eventos de um certo tipo; no denominador, o número de outro tipo de evento" (Pereira, 2002 p.54). No presente estudo, o índice de absenteísmo incorpora, no numerador, o número de dias de ausências não previstas apresentadas pela categoria profissional ao longo do período (1 ano) e, no denominador, o número de dias em que a unidade de saúde deve contar com os trabalhadores de enfermagem, a fim de efetivar o atendimento à clientela (365 dias), o número médio de profissionais e o número de ausências não previstas. Segundo Pereira (2002), um índice com tais características, ou seja, que inclui no denominador informações já contempladas no numerador, constitui-se em uma distribuição proporcional.

Quando se utiliza o IA para planejamento de recursos humanos, em particular, o dimensionamento de pessoal, ele traduzirá a percentagem da força de trabalho que embora alocada na instituição, deixou de ser empregada em determinado período. Por ex. se o índice encontrado é de $5 \%$ em um ano, significa que apenas $95 \%$ da força de trabalho atuou efetivamente no desenvolvimento das atividades previstas/planejadas; caso se pretenda uma força de trabalho de $100 \%$, será necessário um adicional de $5 \%$ de pessoal para compensar o absenteísmo ocorrido no período. (Chiavenato, 1997).

A seguir, são apresentadas as tabelas referentes ao número de

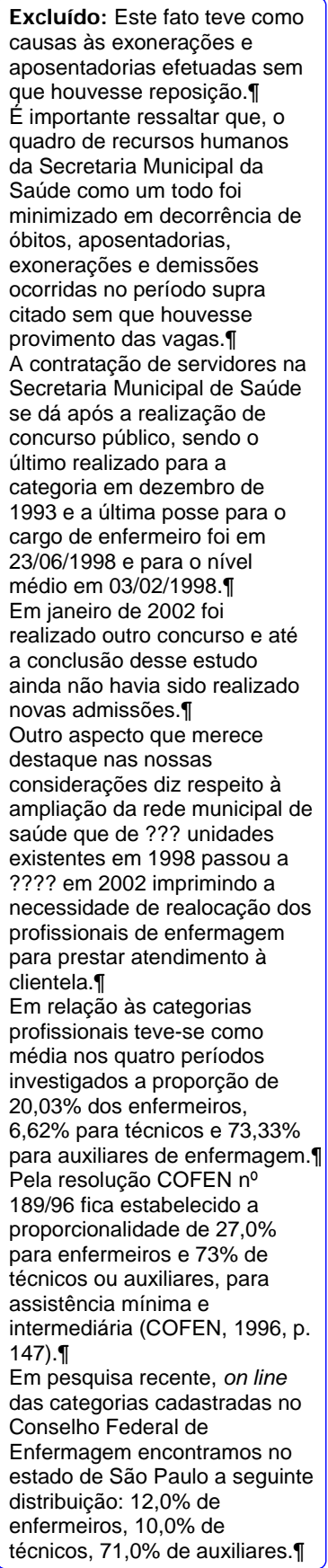


dias de ausência e índice de absenteísmo, para cada período de estudo, segundo categoria profissional dos trabalhadores de enfermagem e tipo de ausência.

Os comentários pertinentes aos índices de absenteísmo período a período serão apresentados de forma consolidada em tabela posterior.

Entre agosto de 1998 e julho de 1999, ocorreram 1.136 dias de ausências para o conjunto de trabalhadores de enfermagem da unidade. Desse total, a maior quantidade de ausências foi de auxiliares de enfermagem (933 dias), bem como o IA (6,75\%); seguido dos enfermeiros com 196 dias e IA de 6,16\%. Os técnicos de enfermagem por sua vez apresentaram o menor número de ausências (sete dias) e menor IA (0,64\%). Em relação ao IA, para o conjunto das três categorias profissionais, o maior índice localiza-se na Licença de Saúde (2,46\%). Nos resultados por categoria, os enfermeiros e auxiliares apresentam índices mais elevados, 3,74\% e 2,33\%, respectivamente, também na Licença de Saúde (Tabela 3). 
Tabela 3. Número médio de pessoal, número de ausências não previstas (em dias) e Índice de Absenteísmo* (IA), segundo categoria profissional e tipo de ausência em uma UBDS. Ribeirão Preto, agosto/1998 a julho/1999.

Tipos de ausência

\begin{tabular}{|c|c|c|c|c|c|c|c|c|c|c|c|c|c|c|c|c|c|c|c|c|c|c|c|}
\hline \multirow{3}{*}{$\begin{array}{l}\text { Categoria } \\
\text { Profissional }\end{array}$} & \multirow{3}{*}{$\begin{array}{l}\mathrm{N}^{\mathrm{o}} \\
\text { médio } \\
\text { de } \\
\text { pessoal }\end{array}$} & \multirow{2}{*}{\multicolumn{2}{|c|}{$\begin{array}{c}\text { Falta } \\
\text { injustificada }\end{array}$}} & \multirow{2}{*}{\multicolumn{2}{|c|}{$\begin{array}{c}\text { Falta } \\
\text { abonada }\end{array}$}} & & & & & & & & & & & & & & & & & & \\
\hline & & & & & & \multicolumn{2}{|c|}{$\begin{array}{l}\text { Licença } \\
\text { Saúde }\end{array}$} & \multicolumn{2}{|c|}{$\begin{array}{c}\text { Licença Ac. } \\
\text { de } \\
\text { Trabalho }\end{array}$} & \multicolumn{2}{|c|}{$\begin{array}{l}\text { Licença } \\
\text { Gestante }\end{array}$} & \multicolumn{2}{|c|}{$\begin{array}{l}\text { Licença } \\
\text { doença em } \\
\text { familiar }\end{array}$} & \multicolumn{2}{|c|}{$\begin{array}{l}\text { Licença } \\
\text { nojo }\end{array}$} & \multicolumn{2}{|c|}{$\begin{array}{l}\text { Licença } \\
\text { prêmio }\end{array}$} & \multicolumn{2}{|c|}{$\begin{array}{l}\text { Licença } \\
\text { paternida } \\
\text { de }\end{array}$} & \multicolumn{2}{|c|}{$\begin{array}{l}\text { Licença } \\
\text { Congresso }\end{array}$} & \multicolumn{2}{|c|}{ TOTAL } \\
\hline & & $\mathrm{N}^{\circ}$ & IA & $\mathrm{N}^{\circ}$ & IA & $\mathrm{N}^{\circ}$ & IA & $\mathrm{N}^{\circ}$ & $\mathrm{IA}$ & $\mathrm{N}^{\circ}$ & IA & $\mathrm{N}^{0}$ & $\mathrm{IA}$ & $\mathrm{N}^{\circ}$ & $\mathrm{IA}$ & No & $\mathrm{IA}$ & $\mathrm{N}^{\circ}$ & $\mathrm{IA}$ & $\mathrm{N}^{\circ}$ & IA & $\mathrm{N}^{\circ}$ & $\mathrm{IA}$ \\
\hline Enfermeiro & 9,25 & 0 & 0 & 1 & 0,03 & 119 & 3,74 & 0 & 0 & 0 & 0 & 0 & 0 & 16 & 0,5 & 60 & 1,89 & 0 & 0 & 0 & 0 & 196 & 6,16 \\
\hline Técnico & 3 & 0 & 0 & 2 & 0,18 & 5 & 0,46 & 0 & 0 & 0 & 0 & 0 & 0 & 0 & 0 & 0 & 0 & 0 & 0 & 0 & 0 & 7 & 0,64 \\
\hline Auxiliar & 40,42 & 30 & 0,22 & 164 & 1,18 & 322 & 2,33 & 170 & 1,23 & 120 & 0,87 & 22 & 0,16 & 0 & 0 & 105 & 0,76 & 0 & 0 & 0 & 0 & 933 & 6,75 \\
\hline TOTAL & 52,67 & 30 & 0,16 & 167 & 0,92 & 446 & 2,46 & 170 & 0,94 & 120 & 0,66 & 22 & 0,12 & 16 & 0,09 & 165 & 0,91 & 0 & 0 & 0 & 0 & 1.136 & 6.28 \\
\hline
\end{tabular}


No período subseqüente (agosto de 1999 a julho de 2000), o total de dias de ausências não previstas sofre uma pequena elevação passando para 1.165 dias, sendo 825 dias correspondentes aos auxiliares de enfermagem, 195 dias aos técnicos e 145 dias de afastamentos dos enfermeiros. Cabe destacar o elevado IA para técnicos de enfermagem (21,66\%) nesse período. Os auxiliares de enfermagem apresentam índice semelhante ao período anterior (6,55\%), enquanto para os enfermeiros há uma redução (4,14\%).

Quanto aos índices obtidos por tipo de ausência nesse período, para todas as categorias, verifica-se que eles são maiores na Licença de Saúde (2,81\%) e na Licença-prêmio (1,26\%). Entretanto, quando se considera a categoria profissional, observa-se que os técnicos apresentam maiores IA em três tipos de ausência, Licença à gestante (13,33\%), Licença por doença em familiar (13,33\%) e Licença de saúde $(3,67 \%)$. Os auxiliares de enfermagem exibem maior IA na Licença de saúde (2,99\%), assim como os enfermeiros (1,97\%) (Tabela 4$)$. 
Tabela 4. Número médio de pessoal, número de ausências não previstas (em dias) e índice de Absenteísmo* (IA), segundo categoria profissional e tipo de ausência em uma UBDS. Ribeirão Preto, agosto/1999 a julho/2000.

Tipo de ausência

\begin{tabular}{|c|c|c|c|c|c|c|c|c|c|c|c|c|c|c|c|c|c|c|c|c|c|c|c|}
\hline \multirow[t]{2}{*}{$\begin{array}{l}\text { Categoria } \\
\text { Profissional }\end{array}$} & \multirow[t]{2}{*}{$\begin{array}{c}\mathrm{N}^{\circ} \\
\text { médio de } \\
\text { pessoal }\end{array}$} & \multicolumn{2}{|c|}{$\begin{array}{c}\text { Falta } \\
\text { injustificada }\end{array}$} & \multicolumn{2}{|c|}{$\begin{array}{c}\text { Falta } \\
\text { abonada }\end{array}$} & \multicolumn{2}{|c|}{$\begin{array}{l}\text { Licença } \\
\text { Saúde }\end{array}$} & \multicolumn{2}{|c|}{$\begin{array}{c}\text { Licença Ac. } \\
\text { de } \\
\text { Trabalho }\end{array}$} & \multicolumn{2}{|c|}{$\begin{array}{l}\text { Licença } \\
\text { Gestante }\end{array}$} & \multicolumn{2}{|c|}{$\begin{array}{l}\text { Licença } \\
\text { doença em } \\
\text { familiar }\end{array}$} & \multicolumn{2}{|c|}{$\begin{array}{l}\text { Licença } \\
\text { nojo }\end{array}$} & \multicolumn{2}{|c|}{$\begin{array}{l}\text { Licença } \\
\text { prêmio }\end{array}$} & \multicolumn{2}{|c|}{$\begin{array}{c}\text { Licença } \\
\text { paternidade }\end{array}$} & \multicolumn{2}{|c|}{$\begin{array}{l}\text { Licença } \\
\text { Congres } \\
\text { so }\end{array}$} & \multicolumn{2}{|c|}{ TOTAL } \\
\hline & & $\mathrm{N}^{\circ}$ & IA & $\mathrm{N}^{\mathrm{O}}$ & IA & $\mathrm{N}^{\circ}$ & IA & $\mathrm{N}^{\circ}$ & IA & $\mathrm{N}^{\mathrm{o}}$ & IA & $\mathrm{N}^{\circ}$ & IA & $\mathrm{N}^{0}$ & IA & $\mathrm{N}^{\circ}$ & IA & $N^{o}$ & IA & $N^{o}$ & IA & $\mathrm{N}^{0}$ & IA \\
\hline Enfermeiro & 10 & 3 & 0,08 & 8 & 0,23 & 69 & 1,97 & 8 & 0,23 & 0 & 0 & 16 & 0,46 & 6 & 0,17 & 35 & 1 & 0 & 0 & 0 & 0 & 145 & 4,14 \\
\hline Técnico & 3 & 7 & 0,78 & 1 & 0,11 & 33 & 3,67 & 0 & 0 & 120 & 13,33 & 12 & 13,33 & 7 & 0,78 & 15 & 1,66 & 0 & 0 & 0 & 0 & 195 & 21,66 \\
\hline Auxiliar & 36,75 & 61 & 0,48 & 132 & 1,05 & 376 & 2,99 & 0 & 0 & 0 & 0 & 31 & 0,25 & 48 & 0,38 & 165 & 1,31 & 12 & 0,09 & 0 & 0 & 825 & 6,55 \\
\hline TOTAL & 49,75 & 71 & 0,42 & 141 & 0,83 & 478 & 2,81 & 8 & 0,05 & 120 & 0,70 & 59 & 0,35 & 61 & 0,36 & 215 & 1,26 & 12 & 0,07 & 0 & 0 & 1.165 & 6,85 \\
\hline
\end{tabular}


De agosto de 2000 a julho de 2001, há uma redução no número de dias perdidos de trabalho, passando para 946 dias. Desse total, 778 dias de ausências não previstas foram apresentados pelos auxiliares, 31 dias pelos técnicos e 137 dias pelos enfermeiros. O IA configura-se maior na categoria de auxiliares (6,52\%), seguido dos enfermeiros $(3,84 \%)$ e por último os técnicos. Nesse período, o maior IA para o conjunto de trabalhadores é de Licença de saúde (2,76\%), seguido da Licença-prêmio $(0,91 \%)$. Na análise por categoria, têm-se na Licença de saúde os maiores índices, sendo para auxiliares 2,9\%, enfermeiros 2,58\% e técnicos 1,88\% (Tabela 5). 
Tabela 5. Número médio de pessoal, número de ausências não previstas (em dias) e Índice de Absenteísmo* (IA), segundo categoria profissional e tipo de ausência em uma UBDS. Ribeirão Preto, agosto/2000 a julho/2001.

Tipo de ausência

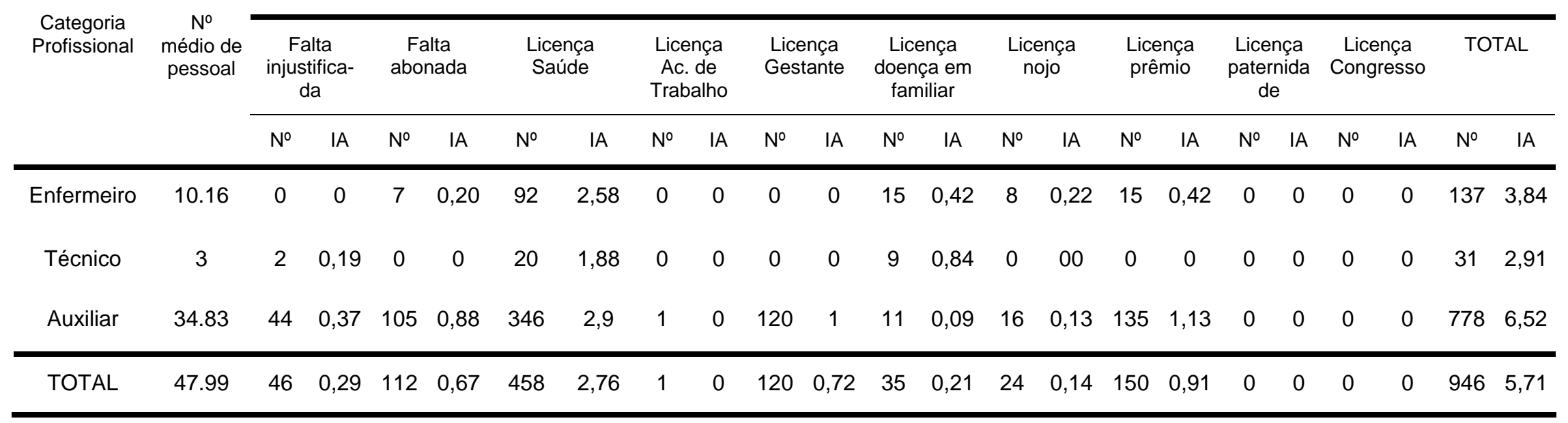


É no quarto período (agosto de 2001 a julho de 2002) que ocorre o maior número de ausências, 1.217 dias, sendo que os auxiliares se ausentaram mais, com 841 dias; seguidos pelos enfermeiros, 255 dias e por fim, os técnicos com 121 dias. Porém, no que se refere ao IA total para o período, nota-se que o maior índice é dos técnicos (9,04\%); em seguida, os auxiliares $(7,53 \%)$ e por último, os enfermeiros (7,51\%). Também nesse período, na análise geral, a Licença de saúde responde pelo maior índice de absenteísmo $(4,46 \%)$ seguida da Licença à gestante (1,03\%). Na análise por categoria, os maiores índices localizam-se também na Licença de saúde, $6,65 \%$ e 4,48\% para técnicos e auxiliares, respectivamente. Já na categoria enfermeiro, o maior IA acontece na Licença à gestante (3,5\%) (Tabela 6). 
Tabela 6. Número médio de pessoal, número de ausências não previstas (em dias) e Índice de Absenteísmo* (IA), segundo categoria profissional e tipo de ausência em uma UBDS. Ribeirão Preto, agosto/2001 a julho/2002.

Tipo de ausência

\begin{tabular}{|c|c|c|c|c|c|c|c|c|c|c|c|c|c|c|c|c|c|c|c|c|c|c|c|}
\hline \multirow[t]{2}{*}{$\begin{array}{l}\text { Categoria } \\
\text { Profissional }\end{array}$} & \multirow[t]{2}{*}{$\begin{array}{c}\mathrm{N}^{\circ} \\
\text { médio de } \\
\text { pessoal }\end{array}$} & \multicolumn{2}{|c|}{$\begin{array}{c}\text { Falta } \\
\text { injustifica- } \\
\text { da }\end{array}$} & \multicolumn{2}{|c|}{$\begin{array}{c}\text { Falta } \\
\text { abonada }\end{array}$} & \multicolumn{2}{|c|}{$\begin{array}{l}\text { Licença } \\
\text { Saúde }\end{array}$} & \multicolumn{2}{|c|}{$\begin{array}{l}\text { Licença Ac. } \\
\text { de Trabalho }\end{array}$} & \multicolumn{2}{|c|}{$\begin{array}{l}\text { Licença } \\
\text { Gestante }\end{array}$} & \multicolumn{2}{|c|}{$\begin{array}{l}\text { Licença } \\
\text { doença em } \\
\text { familiar }\end{array}$} & \multicolumn{2}{|c|}{$\begin{array}{l}\text { Licença } \\
\text { nojo }\end{array}$} & \multicolumn{2}{|c|}{$\begin{array}{l}\text { Licença } \\
\text { prêmio }\end{array}$} & \multicolumn{2}{|c|}{$\begin{array}{l}\text { Licen- } \\
\text { ça } \\
\text { paterni } \\
\text { dade }\end{array}$} & \multicolumn{2}{|c|}{$\begin{array}{l}\text { Licença } \\
\text { Congres } \\
\text { so }\end{array}$} & \multicolumn{2}{|c|}{ TOTAL } \\
\hline & & $\mathrm{N}^{\circ}$ & IA & $\mathrm{N}^{\circ}$ & IA & $\mathrm{N}^{0}$ & IA & $\mathrm{N}^{\circ}$ & IA & $\mathrm{N}^{\circ}$ & $\mathrm{IA}$ & $\mathrm{N}^{\circ}$ & $\mathrm{IA}$ & $\mathrm{N}^{\circ}$ & IA & $\mathrm{N}^{\circ}$ & IA & $\mathrm{N}^{\circ}$ & IA & $\mathrm{N}^{\circ}$ & $\mathrm{IA}$ & $\mathrm{N}^{\circ}$ & $\mathrm{IA}$ \\
\hline Enfermeiro & 10 & 3 & 0,09 & 7 & 0,20 & 119 & 3,47 & 0 & 0 & 120 & 3,5 & 1 & 0,03 & 0 & 0 & 0 & 0 & 0 & 0 & 5 & 0,15 & 255 & 7,51 \\
\hline Técnico & 4 & 6 & 0,45 & 0 & 0 & 89 & 6,65 & 0 & 0 & 0 & 0 & 10 & 0,75 & 16 & 1,19 & 0 & 0 & 0 & 0 & 0 & 0 & 121 & 9,04 \\
\hline Auxiliar & 32,91 & 45 & 0,41 & 79 & 0,71 & 501 & 4,48 & 30 & 0,27 & 44 & 0,39 & 43 & 0,38 & 24 & 0,21 & 75 & 0,67 & 0 & 0 & 0 & 0 & 841 & 7,53 \\
\hline TOTAL & 46,91 & 54 & 0,34 & 86 & 0,54 & 709 & 4,46 & 30 & 0,19 & 164 & 1,03 & 54 & 0,34 & 40 & 0,25 & 75 & 0,47 & 0 & 0 & 5 & 0,03 & 1.217 & 7,6 \\
\hline
\end{tabular}


$\mathrm{Na}$ Tabela 7, buscou-se consolidar os dados relativos ao número de dias de ausências e IA, segundo categoria profissional em todo o período estudado. A Figura 1 possibilita melhor visualização das informações referentes ao IA.

Tabela 7. Distribuição do número de dias de ausência e respectivo Índice de Absenteísmo (IA), segundo categoria profissional e período em uma UBDS. Ribeirão Preto, agosto/1998 a julho/2002.

\begin{tabular}{|c|c|c|c|c|c|c|c|c|c|c|}
\hline \multirow{3}{*}{$\begin{array}{l}\text { Categoria } \\
\text { Profissional }\end{array}$} & \multicolumn{10}{|c|}{ PERÍODO } \\
\hline & \multicolumn{2}{|c|}{$1^{\circ}$} & \multicolumn{2}{|c|}{$2^{\circ}$} & \multicolumn{2}{|c|}{$3^{\circ}$} & \multicolumn{2}{|c|}{$4^{\circ}$} & \multicolumn{2}{|c|}{ TOTAL } \\
\hline & $\mathbf{N}$ & IA & $\mathrm{N}^{0}$ & IA & $\mathbf{N}^{\circ}$ & IA & $\mathbf{N}^{\circ}$ & IA & $\mathbf{N}^{\circ}$ & IA \\
\hline Enfermeiro & 196 & 6,16 & 145 & 4,14 & 137 & 3,84 & 255 & 7,51 & 733 & 5,37 \\
\hline Técnico & 7 & 0,64 & 195 & 21,66 & 31 & 2,91 & 121 & 9,04 & 354 & 8,06 \\
\hline Auxiliar & 933 & 6,75 & 825 & 6,55 & 778 & 6,52 & 841 & 7,53 & 3.377 & 6,82 \\
\hline TOTAL & 1.136 & 6,28 & 1.165 & 6,85 & 946 & 5,71 & 1.217 & 7,65 & 4.464 & 6,61 \\
\hline
\end{tabular}

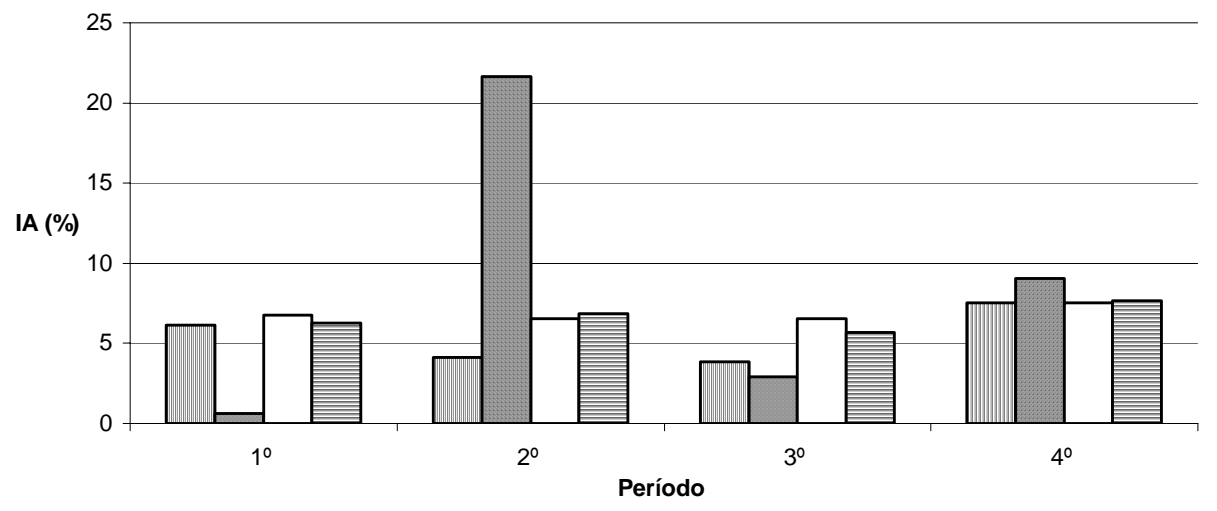

$\square$ Enfermeiro $\square$ Técnico $\square$ Auxiliar 目Total

Figura 1. Índice de Absenteísmo de pessoal de enfermagem, segundo período de estudo e categoria profissional em uma UBDS. Ribeirão Preto, agosto/1998 a julho/2002. 
Observa-se que o IA médio geral para os quatro períodos estudados foi de $6,61 \%$, ou seja, do total do tempo/trabalho esperado da equipe de enfermagem nesses quatro anos, aproximadamente $7 \%$ desse tempo ficou comprometido devido às ausências não previstas. A categoria técnico de enfermagem foi a que apresentou maior IA (8,06\%), explicado talvez em parte pelos índices elevados que a categoria apresentou no $2^{\circ}$ período $(21,66 \%)$ e no $4^{\circ}$ período $(9,04 \%)$; em seguida, tem-se o IA médio dos auxiliares de enfermagem (6,82\%), sendo que, ao longo do período, a categoria apresenta índices variando de 6,52\% a 7,53\%. Quanto aos enfermeiros, o IA médio geral foi o mais baixo (5,37\%), porém, durante os quatro anos, essa categoria mostra índices variáveis, entre $3,84 \%$ (no $3^{\circ}$ período) a $7,44 \%$ (no $4^{\circ}$ período).

Na Figura 2, detalha-se o IA por período, depreende-se que em média as ausências não previstas responderam por aproximadamente entre 6 a $8 \%$ do tempo perdido de trabalho na unidade para a equipe de enfermagem. O índice mais relevante está no quarto período atingindo $7,65 \%$, este, quando comparado ao índice do primeiro período, evidencia um aumento de 1,37\% no volume de ausências. 


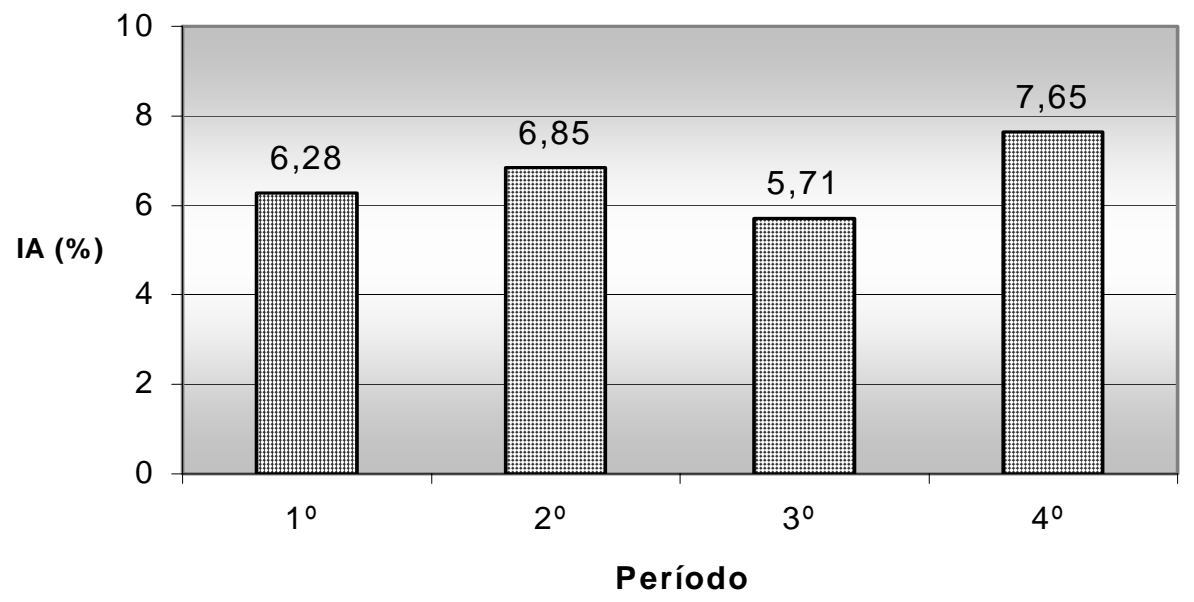

Figura 2. Índice geral de Absenteísmo (\%) para equipe de enfermagem, segundo período de estudo numa UBDS. Ribeirão Preto-SP, agosto/1998 a julho/2002.

Esse índice pode estar relacionado a aumento da demanda de atendimento, visto que houve um crescimento em torno de $34 \%$ no volume de consultas médicas, o que leva a uma sobrecarga de trabalho e, conseqüentemente, a maior número de afastamentos, mesmo sendo o menor índice alcançado no período de agosto/2000 a julho/2001.

Há que se destacar o fato de que na unidade estudada, auxiliares e técnicos de enfermagem desenvolvem atividades semelhantes, assim, as ausências não previstas dessas duas categorias de profissionais apresentam um grande impacto nas atividades realizadas.

O motivo e a duração do afastamento, na maioria das vezes, não são do conhecimento da chefia imediata ou até mesmo da gerência local, não sendo possível providenciar a substituição do funcionário, o que acaba sobrecarregando os demais trabalhadores do plantão.

Em 1994, através da Lei Complementar 406, a Secretaria 
Municipal de Saúde instituiu o critério assiduidade, por meio do qual aqueles servidores que não apresentassem nenhum tipo de afastamento no mês teriam acrescido aos seus provimentos um valor correspondente a $3 \%$ do salário-base.

Embora não se tenha efetuado nenhum levantamento acerca das ausências anteriores à implantação dessa premiação, acredita-se que esta tenha surtido impacto na redução das ausências não previstas.

Ressaltamos também que, em muitas ocasiões, mediante autorização da chefia do plantão, muitas ausências não previstas, principalmente as faltas, são negociadas descontando-se do saldo de horas em haver do funcionário, assim como são autorizadas as trocas de folga na escala, a fim de não comprometer o recebimento do adicional supracitado. Desse modo, os índices de absenteísmo verificados no presente estudo são passíveis de questionamentos, uma vez que em função da estratégia acima descrita, podem estar minimizados, ou seja, não representarem efetivamente o tempo/trabalho perdido na UBDS.

Em consulta à literatura produzida nacionalmente sobre absenteísmo no trabalho de enfermagem, encontramos apenas estudos desenvolvidos na área hospitalar, a qual apresenta uma dinâmica de trabalho diferenciada em termos de complexidade da assistência ofertada à clientela, que por sua vez traz implicações no tipo e volume de atividades de enfermagem e, por conseqüência, na própria organização do trabalho. Em uma Unidade Básica e Distrital de Saúde dadas as características da demanda, as ações de enfermagem exibem um menor grau de 
complexidade, porém não menos importante, que comportam: procedimentos técnicos como coleta de exames, administração de medicamentos, curativos, testes de sensibilidade; e ainda, pré e pósconsulta de enfermagem, orientações, visita domiciliária entre outras. Entretanto, respeitadas as diferenças, acreditamos ser possível estabelecer comparações entre os resultados obtidos neste estudo e aqueles encontrados nas investigações da área hospitalar.

Com base nos dados apresentados na Tabela 7, tomando em particular, o índice de absenteísmo geral para cada categoria, buscamos na literatura estudos cujos resultados permitissem comparações àqueles obtidos nesta pesquisa.

Belém et al. (1998), ao desenvolver uma pesquisa em um hospital geral de grande porte, estudaram as ausências não previstas do pessoal de enfermagem das unidades de internação, centro cirúrgico, UTI geral e pediátrica e constataram um índice médio de 3\% de absenteísmo.

Pavani (2000) identificoųpara duas unidades de Rę̧cuperação Cardíaca (I e II $)_{2}$ de um hospital especializado em cardiologia ${ }_{1}$ os seguintes índices de ausências não previstas; na unidade I, 2,94\% para enfermeiros,

Excluído: no seu estudo observou que o percentual de ausências não previstas dentro da

Excluído: $\mathrm{Re}$ Excluído: C

Excluído: foi de 0,79\% para técnicos e 12,18\% para auxiliares de enfermagem, com IA médio geral de 6,51\%; e, na Recuperação Cardíaca II, de 1,96\% para enfermeiros, 0,93\% para técnicos, $12,55 \%$ para os auxiliares e IA médio geral de $8,98 \%$.

Tanos et al. (2000) ao analisar o absenteísmo do pessoal de enfermagem em uma unidade especializada em transplante de fígado, 
encontraram um índice de 9\% para enfermeiros e 17\% para auxiliares de enfermagem.

O índice de absenteísmo da equipe de enfermagem do centro cirúrgico de um hospital público encontrado por Possari (2001), no ano de 1998 pode ser considerado o mais elevado, sendo de $14,28 \%$ para enfermeiros; de $15,48 \%$ para auxiliares de enfermagem e o IA médio geral de $15,35 \%$. O autor comenta que tais valores devem ser tomados com cautela, quando se pensa em utilizá-los para fins de dimensionamento de pessoal, especificamente no que diz respeito à cobertura das ausências.

Investigação desenvolvida em um hospital universitário, envolvendo unidades de clínica médica, cirúrgica, terapia intensiva de adulto, terapia intensiva pediátrica, pediatria, berçário e alojamento conjunto, no ano de 2000, aponta IA para enfermeiros variando de 1,26\% a 5,34\%; e de 1,55\% a 12,06\% para técnicos e auxiliares de enfermagem, com índice médio geral de 5,87\% (Fugulin, 2002).

Laus (2003) no seu estudo sobre dimensionamento de pessoal para unidades de internação médica e cirúrgica de um hospital-escola, encontrou para o período de abril de 2001 a março de 2002, um índice médio geral de 5,5\%, e, especificamente, $5,1 \%$ para enfermeiros e 5,6\% para os técnicos e auxiliares de enfermagem.

Farias (2003) avaliando as ausências não previstas do pessoal de enfermagem em um Pronto-Socorro de hospital público, encontrou índices de absenteísmo de 1,67\% para enfermeiros, de 4,33\%, para os auxiliares de enfermagem e IA médio geral de 3,87\%, considerado baixo, o 
que para a autora revela o comprometimento do pessoal com o serviço.

O IA verificado em nossa pesquisa, para enfermeiros, foi de 5,37\% que se mostra superior aos índices obtidos nos estudos de Belém et al. (1998), Pavani (2000), Fugulin (2002), Laus (2003) e Farias (2003); e, inferior àquele identificado por Tanos et al. (2000) e Possari (2001).

Quanto ao pessoal de nível médio, os resultados foram: 8,06\% para técnicos e 6,82\% para auxiliares de enfermagem. Apenas Pavani (2000) analisou ausências não previstas de forma distinta para técnicos e auxiliares. Os resultados obtidos pela autora diferem dos nossos em ambas as categorias de trabalhadores. Os auxiliares apresentaram IA superior aos técnicos, enquanto na UBDS estudada esta categoria de trabalhador foi quem respondeu por índices de absenteísmo mais elevados.

Os demais autores investigaram o absenteísmo tomando conjuntamente auxiliares e técnicos, o que dificulta estabelecer comparações com os resultados aqui apresentados. Entretanto, observa-se que, nos estudos consultados, o absenteísmo entre técnicos/auxiliares é sempre maior que o dos enfermeiros, o que também pode ser evidenciado nesta pesquisa.

Outro aspecto a destacar é que o absenteísmo resulta de múltiplos determinantes: pessoais, da dinâmica de organização e das condições de trabalho, do processo de gerência, da motivação e valorização do trabalhador. Os estudos da Organizacion Internacional Del Trabajo $(O I T, 1989)$ demonstram que os índices de ausências não previstas variam com o tipo de atividade laboral, o grau de escolaridade, o sexo e as 
condições de trabalho. Tais elementos, de certa forma, inviabilizam estabelecer comparações entre os vários estudos no sentido de apontar se os valores obtidos são elevados ou não. Segundo Gaidzinski (1998), quando se trata de inserir, na equação do dimensionamento de pessoal, os índices de absenteísmo obtidos com vistas à cobertura das ausências não previstas, é necessário avaliar com prudência os valores obtidos. Índices de absenteísmo elevados podem provocar distorções na projeção do quadro de pessoal, superestimando-o. Assim, a autora considera que o IA adequado seria de 4,3\% para enfermeiros e 6,7\% para o pessoal de nível médio. Com base nesse parâmetro, podem se considerar elevados os índices de absenteísmo na Distrital de Saúde pesquisada, nas três categorias de profissionais.

\section{2_Distribuição dos tipos de ausência não prevista}

A seguir, são apresentados os resultados relativos à distribuição dos tipos de ausências não previstas, por período e categoria profissional. $\mathrm{Na}$ análise do IA exposto anteriormente, verificou-se que as licenças por nojo, paternidade e participação em Congresso ocorreram de forma bastante reduzida, assim, nas tabelas que se seguem, tais tipos de ausências foram agrupadas na categoria "outras licenças".

Observamos que, no primeiro período, do total de ausências não previstas, a licença de saúde respondeu pelo maior percentual $(39,26 \%)$, seguida da falta abonada $(14,7 \%)$ e licença-prêmio (14,52\%) 
(Tabela 8).

No que se refere às categorias profissionais, todas apresentam percentuais mais elevados de licença de saúde, a saber: 71,43\% para técnicos, 60,71\% para enfermeiros e 34,5\% para auxiliares.

O segundo tipo de ausência mais freqüente foi, para os enfermeiros, a licença-prêmio (30,62\%); enquanto para os técnicos, a falta abonada $(28,57)$ e para os auxiliares, licença por acidente de trabalho $(18,22 \%)$

Excluído: ๆ 
Tabela 8. Distribuição das ausências não previstas (em dias) dos trabalhadores de enfermagem, segundo categoria profissional e tipo de ausência em uma UBDS. Ribeirão Preto, agosto/1998 a julho/1999.

\begin{tabular}{|c|c|c|c|c|c|c|c|c|c|c|c|c|c|c|c|c|c|c|}
\hline \multirow{3}{*}{$\begin{array}{l}\text { Categoria } \\
\text { Profissional }\end{array}$} & \multicolumn{18}{|c|}{$\underline{\text { Tipo de ausência }}$} \\
\hline & \multicolumn{2}{|c|}{ 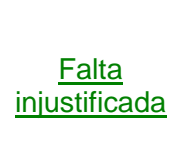 } & \multicolumn{2}{|c|}{$\begin{array}{c}\text { Falta } \\
\text { abonada }\end{array}$} & \multicolumn{2}{|c|}{ Licença Saúde } & \multicolumn{2}{|c|}{$\begin{array}{l}\text { Licenca Ac. } \\
\text { de Trabalho }\end{array}$} & \multicolumn{2}{|c|}{$\begin{array}{l}\text { Licença } \\
\underline{\text { Gestante }}\end{array}$} & \multicolumn{2}{|c|}{$\frac{\text { Licença doença }}{\text { em familiar }}$} & \multicolumn{2}{|c|}{ Licença Prêmio } & \multicolumn{2}{|c|}{$\begin{array}{c}\frac{\text { Outras licenças }}{\text { (nojo, }} \\
\frac{\text { paternidade, }}{\text { Congresso) }}\end{array}$} & \multicolumn{2}{|c|}{$\underline{\text { TOTAL }}$} \\
\hline & $\underline{\text { No }^{\circ}}$ & $\%$ & $\underline{\text { No }}$ & $\underline{\%}$ & $\underline{N^{\circ}}$ & $\%$ & $\underline{N^{0}}$ & $\%$ & $\underline{N^{\circ}}$ & $\%$ & $\underline{N^{0}}$ & $\%$ & $\underline{N^{0}}$ & $\%$ & $\underline{\text { No}^{\circ}}$ & $\%$ & $\underline{\text { No}^{\circ}}$ & $\underline{\%}$ \\
\hline Enfermeiro & $\underline{0}$ & $\underline{0}$ & $\underline{1}$ & $\underline{0,51}$ & $\underline{119}$ & $\underline{60,71}$ & $\underline{0}$ & $\underline{0}$ & $\underline{0}$ & $\underline{0}$ & $\underline{0}$ & $\underline{0}$ & $\underline{60}$ & $\underline{30,62}$ & $\underline{16}$ & $\underline{8,16}$ & $\underline{196}$ & $\underline{100}$ \\
\hline$\underline{\text { Técnico }}$ & $\underline{0}$ & $\underline{0}$ & $\underline{2}$ & $\underline{28,57}$ & $\underline{5}$ & $\underline{71,42}$ & $\underline{0}$ & $\underline{0}$ & $\underline{0}$ & $\underline{0}$ & $\underline{0}$ & $\underline{0}$ & $\underline{0}$ & $\underline{0}$ & $\underline{0}$ & $\underline{0}$ & $\underline{7}$ & $\underline{100}$ \\
\hline$\underline{\text { Auxiliar }}$ & $\underline{30}$ & $\underline{3,21}$ & $\underline{164}$ & $\underline{17,57}$ & $\underline{322}$ & $\underline{34,5}$ & $\underline{170}$ & $\underline{18,22}$ & $\underline{120}$ & $\underline{12,86}$ & $\underline{22}$ & $\underline{2,35}$ & $\underline{105}$ & $\underline{11,25}$ & $\underline{0}$ & $\underline{0}$ & $\underline{933}$ & $\underline{100}$ \\
\hline TOTAL & $\underline{30}$ & $\underline{2,64}$ & 167 & 14,70 & $\underline{446}$ & $\underline{39,26}$ & $\underline{170}$ & $\underline{15}$ & $\underline{120}$ & $\underline{10,56}$ & $\underline{22}$ & $\underline{1,93}$ & $\underline{165}$ & $\underline{14,52}$ & $\underline{16}$ & $\underline{1,4}$ & 1.136 & 100 \\
\hline
\end{tabular}


Quanto ao período de agosto de 1999 a julho de 2000, observa-se que novamente para todas as categorias de trabalhadores, a licença de saúde teve o percentual mais expressivo (41,03\%); a licença-prêmio foi o segundo tipo de ausência mais freqüente (18,45\%) (Tabela 9).

Particularizando a análise para as diferentes categorias, para enfermeiros e auxiliares, os maiores percentuais são de licença de saúde, $47,59 \%$ e $45,57 \%$, respectivamente, enquanto para os técnicos foi a licença à gestante $(61,54 \%)$.

Novamente, há que se destacar a licença-prêmio como segunda maior causa de ausência não prevista para os enfermeiros $(24,14 \%)$ e para os auxiliares de enfermagem (20,0\%). Já para técnicos, foi a licença de saúde que representou $16,92 \%$ das ausências. 
Tabela 9. Distribuição das ausências não previstas (em dias) dos trabalhadores de enfermagem, segundo categoria profissional e tipo de ausência em uma UBDS. Ribeirão Preto, agosto/1999 a julho/2000.

\begin{tabular}{|c|c|c|c|c|c|c|c|c|c|c|c|c|c|c|c|c|c|c|}
\hline \multirow{3}{*}{$\frac{\text { Categoria }}{\text { Profissional }}$} & \multicolumn{18}{|c|}{ Tipo de ausência } \\
\hline & \multicolumn{2}{|c|}{$\underline{\text { injustificada }}$} & \multicolumn{2}{|c|}{$\begin{array}{c}\frac{\text { Falta }}{\text { abonada }} \\
\underline{\text { bind }}\end{array}$} & \multicolumn{2}{|c|}{ Licença Saúde } & \multicolumn{2}{|c|}{ 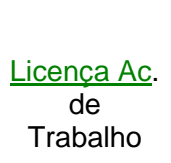 } & \multicolumn{2}{|c|}{$\begin{array}{l}\underline{\text { Licença }} \\
\underline{\text { Gestante }}\end{array}$} & \multicolumn{2}{|c|}{$\frac{\text { Licença doença }}{\text { em familiar }}$} & \multicolumn{2}{|c|}{ Licença Prêmio } & \multicolumn{2}{|c|}{$\begin{array}{l}\frac{\text { Outras licenças }}{\text { (nojo, }} \\
\frac{\text { paternidade, }}{\text { Congresso) }}\end{array}$} & \multicolumn{2}{|c|}{$\underline{\text { TOTAL }}$} \\
\hline & $\underline{N^{0}}$ & $\underline{\%}$ & $\underline{N^{\circ}}$ & $\underline{\%}$ & $\underline{N^{\circ}}$ & $\%$ & $\underline{N^{0}}$ & $\underline{\%}$ & $\underline{N^{0}}$ & $\underline{\%}$ & $\underline{N^{\circ}}$ & $\underline{\%}$ & $\underline{N^{\circ}}$ & $\underline{\%}$ & $\underline{N^{0}}$ & \% & $\underline{\text { No }^{\circ}}$ & $\underline{\%}$ \\
\hline Enfermeiro & $\underline{3}$ & $\underline{2,07}$ & $\underline{8}$ & $\underline{5,52}$ & $\underline{69}$ & $\underline{47,59}$ & $\underline{8}$ & $\underline{5,52}$ & $\underline{0}$ & $\underline{0}$ & $\underline{16}$ & $\underline{11,03}$ & $\underline{35}$ & $\underline{24,14}$ & $\underline{6}$ & $\underline{4,13}$ & $\underline{145}$ & $\underline{100}$ \\
\hline$\underline{\text { Técnico }}$ & $\underline{7}$ & $\underline{3,59}$ & $\underline{1}$ & $\underline{0,51}$ & $\underline{33}$ & $\underline{16,92}$ & $\underline{0}$ & $\underline{0}$ & $\underline{120}$ & $\underline{61,54}$ & $\underline{12}$ & $\underline{6,15}$ & $\underline{15}$ & $\underline{7,69}$ & $\underline{7}$ & 3,60 & $\underline{195}$ & $\underline{100}$ \\
\hline Auxiliar & $\underline{61}$ & 7,4 & $\underline{132}$ & $\underline{16}$ & $\underline{376}$ & $\underline{45,57}$ & $\underline{0}$ & $\underline{0}$ & $\underline{0}$ & $\underline{0}$ & $\underline{31}$ & $\underline{3,76}$ & $\underline{165}$ & $\underline{20}$ & $\underline{60}$ & $\underline{7,27}$ & $\underline{825}$ & 100 \\
\hline TOTAL & $\underline{71}$ & $\underline{6}, 10$ & $\underline{141}$ & $\underline{12,1}$ & $\underline{478}$ & $\underline{41,03}$ & $\underline{8}$ & $\underline{0,69}$ & $\underline{120}$ & $\underline{10,30}$ & $\underline{59}$ & $\underline{5,06}$ & $\underline{215}$ & $\underline{18,45}$ & $\underline{73}$ & $\underline{6,27}$ & 1.165 & $\underline{100}$ \\
\hline
\end{tabular}


No $3^{\circ}$ período, aproximadamente $50 \%$ das ausências não previstas para as três categorias ocorreu na licença de saúde (Tabela 10).

Esse mesmo tipo de ausência responde por $67,15 \%$ do absenteísmo dos enfermeiros $64,52 \%$ dos técnicos e $44,47 \%$ dos auxiliares de enfermagem.

Em segundo lugar, para os enfermeiros, tem-se a licençaprêmio com $10,95 \%$ e a doença em familiar também com 10,95\%; e para os técnicos e auxiliares de enfermagem, a licença motivada por doença em pessoa da família e a licença-prêmio apresentaram índices correspondentes a $29 \%$ e $17,35 \%$, respectivamente. 
Tabela 10. Distribuição das ausências não previstas (em dias) dos trabalhadores de enfermagem, segundo categoria profissional e tipo de ausência em uma UBDS. Ribeirão Preto, agosto/2000 a julho/2001.

\begin{tabular}{|c|c|c|c|c|c|c|c|c|c|c|c|c|c|c|c|c|c|c|}
\hline \multirow{3}{*}{$\frac{\text { Categoria }}{\text { Profissional }}$} & \multicolumn{18}{|c|}{$\underline{\text { Tipo de ausência }}$} \\
\hline & \multicolumn{2}{|c|}{$\underline{\text { injustificada }}$} & \multicolumn{2}{|c|}{$\begin{array}{c}\text { Falta } \\
\text { abonada }\end{array}$} & \multicolumn{2}{|c|}{ Licença Saúde } & \multicolumn{2}{|c|}{$\frac{\text { Licença Ac. }}{\text { de Trabalho }}$} & \multicolumn{2}{|c|}{$\begin{array}{l}\underline{\text { Licença }} \\
\underline{\text { Gestante }}\end{array}$} & \multicolumn{2}{|c|}{$\frac{\text { Licença doença }}{\text { em familiar }}$} & \multicolumn{2}{|c|}{ Licença Prêmio } & \multicolumn{2}{|c|}{$\frac{\text { Outras licenças }}{\frac{\text { (nojo, }}{\text { paternidade, }}}$} & \multicolumn{2}{|c|}{ TOTAL } \\
\hline & № & $\underline{\%}$ & $\mathrm{~N}^{0}$ & $\underline{\%}$ & $\underline{N^{0}}$ & $\underline{\%}$ & $\underline{N}^{\circ}$ & $\underline{\%}$ & № & $\underline{\%}$ & $\underline{N^{0}}$ & $\underline{\%}$ & $\underline{\mathrm{N}^{0}}$ & $\underline{\%}$ & № & $\underline{\%}$ & $\underline{N^{0}}$ & $\underline{\%}$ \\
\hline Enfermeiro & $\underline{0}$ & $\underline{0}$ & $\underline{7}$ & $\underline{5,11}$ & $\underline{92}$ & $\underline{67,15}$ & $\underline{0}$ & $\underline{0}$ & $\underline{0}$ & $\underline{0}$ & $\underline{15}$ & $\underline{10,95}$ & $\underline{15}$ & $\underline{10,95}$ & $\underline{8}$ & $\underline{5,84}$ & $\underline{137}$ & $\underline{100}$ \\
\hline Técnico & $\underline{2}$ & $\underline{6,45}$ & $\underline{0}$ & $\underline{0}$ & $\underline{20}$ & $\underline{64,52}$ & $\underline{0}$ & $\underline{0}$ & $\underline{0}$ & $\underline{0}$ & $\underline{9}$ & $\underline{29}, 03$ & $\underline{0}$ & $\underline{0}$ & $\underline{0}$ & $\underline{0}$ & $\underline{31}$ & $\underline{100}$ \\
\hline Auxiliar & $\underline{44}$ & $\underline{5,66}$ & $\underline{105}$ & $\underline{13,50}$ & $\underline{346}$ & $\underline{44,47}$ & $\underline{1}$ & $\underline{0,13}$ & $\underline{120}$ & $\underline{15,42}$ & $\underline{11}$ & $\underline{1,41}$ & $\underline{135}$ & $\underline{17,35}$ & $\underline{16}$ & $\underline{2,06}$ & $\underline{778}$ & $\underline{100}$ \\
\hline TOTAL & 46 & $\underline{4,86}$ & 112 & $\underline{11,84}$ & $\underline{458}$ & $\underline{48,41}$ & $\underline{1}$ & $\underline{0,11}$ & $\underline{120}$ & $\underline{12,68}$ & 35 & $\underline{3,7}$ & $\underline{150}$ & $\underline{15,86}$ & $\underline{24}$ & 2,54 & $\underline{946}$ & 100 \\
\hline
\end{tabular}


No último período, à semelhança dos demais, a licença de saúde responde por aproximadamente $60 \%$ das ausências de todo o grupo de trabalhadores, seguida da licença à gestante (13,47\%) (Tabela 11).

A licença à gestante $(47,05 \%)$ e de saúde (46,67\%) representam os percentuais mais expressivos de ausência não prevista para os enfermeiros.

Já em relação aos técnicos de enfermagem se sobressaem as licenças de saúde (73,55\%) e outras licenças (13,22\%).

$\mathrm{Na}$ categoria dos auxiliares de enfermagem, temos o percentual mais elevado na licença de saúde $(59,57 \%)$ e na falta abonada $(9,39 \%)$. 
Tabela 11. Distribuição das ausências não previstas (em dias) dos trabalhadores de enfermagem, segundo categoria profissional e tipo de ausência em uma UBDS. Ribeirão Preto, agosto/2001 a julho/2002.

\begin{tabular}{|c|c|c|c|c|c|c|c|c|c|c|c|c|c|c|c|c|c|c|}
\hline \multirow{3}{*}{ 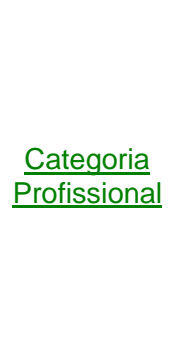 } & \multicolumn{18}{|c|}{$\underline{\text { Tipo de ausência }}$} \\
\hline & \multicolumn{2}{|c|}{ Falta injustificada } & \multicolumn{2}{|c|}{$\begin{array}{c}\text { Falta } \\
\text { abonada }\end{array}$} & \multicolumn{2}{|c|}{$\underline{\text { Licença Saúde }}$} & \multicolumn{2}{|c|}{$\frac{\text { Licença Ac. }}{\text { de Trabalho }}$} & \multicolumn{2}{|c|}{$\begin{array}{l}\text { Licença } \\
\underline{\text { Gestante }}\end{array}$} & \multicolumn{2}{|c|}{$\frac{\underline{\text { Licença }}}{\underline{\text { doença em }}}$} & \multicolumn{2}{|c|}{$\frac{\text { Licença }}{\underline{\text { Prêmio }}}$} & \multicolumn{2}{|c|}{$\frac{\frac{\text { Outras licenças }}{\text { (nojo, }}}{\frac{\underline{\text { paternidade }}}{\text { Congresso) }}}$} & \multicolumn{2}{|c|}{$\underline{\text { TOTAL }}$} \\
\hline & $\underline{N^{0}}$ & $\underline{\%}$ & $\mathrm{~N}^{0}$ & $\underline{\%}$ & $\underline{\text { No }^{\circ}}$ & $\underline{\%}$ & $\underline{N^{0}}$ & $\underline{\%}$ & $\underline{N^{\circ}}$ & $\underline{\%}$ & $\underline{N^{0}}$ & $\underline{\%}$ & $\underline{N^{0}}$ & $\underline{\%}$ & $\underline{N^{\circ}}$ & $\underline{\%}$ & $\underline{N^{0}}$ & $\underline{\%}$ \\
\hline Enfermeiro & $\underline{3}$ & $\underline{1,18}$ & $\underline{7}$ & $\underline{2,75}$ & $\underline{119}$ & $\underline{46,67}$ & $\underline{0}$ & $\underline{0}$ & $\underline{120}$ & $\underline{47,05}$ & $\underline{1}$ & $\underline{0,39}$ & $\underline{0}$ & $\underline{0}$ & $\underline{5}$ & $\underline{1,96}$ & $\underline{255}$ & $\underline{100}$ \\
\hline Técnico & $\underline{6}$ & $\underline{4,96}$ & $\underline{0}$ & $\underline{0}$ & $\underline{89}$ & $\underline{73,55}$ & $\underline{0}$ & $\underline{0}$ & $\underline{0}$ & $\underline{0}$ & $\underline{10}$ & $\underline{8,26}$ & $\underline{0}$ & $\underline{0}$ & $\underline{16}$ & $\underline{13,22}$ & $\underline{121}$ & $\underline{100}$ \\
\hline Auxiliar & $\underline{45}$ & $\underline{5,47}$ & $\underline{79}$ & $\underline{9,39}$ & $\underline{501}$ & $\underline{59,57}$ & $\underline{30}$ & $\underline{3,58}$ & 44 & $\underline{5,23}$ & $\underline{43}$ & $\underline{5,11}$ & $\underline{75}$ & $\underline{8,92}$ & $\underline{24}$ & $\underline{2,85}$ & $\underline{841}$ & $\underline{100}$ \\
\hline TOTAL & $\underline{54}$ & $\underline{4,44}$ & $\underline{86}$ & $\underline{7,07}$ & $\underline{709}$ & $\underline{58,26}$ & $\underline{30}$ & $\underline{2,46}$ & $\underline{164}$ & $\underline{13,47}$ & $\underline{54}$ & $\underline{4,44}$ & $\underline{75}$ & $\underline{6,16}$ & $\underline{45}$ & $\underline{3,70}$ & 1.217 & $\underline{100}$ \\
\hline
\end{tabular}


Consolidando os dados obtidos nos quatro períodos (Tabela 12), verifica-se, para todo o grupo, que a licença de saúde $(46,84 \%)$, licençaprêmio (13,55\%) e licença a gestante $(11,73 \%)$ são as ausências mais freqüentes.

Analisando cada categoria, nota-se que tanto os enfermeiros, como técnicos e auxiliares ausentaram-se mais devido à licença de saúde: $54,43 \%, 41,52 \%$ e 45,75\%, respectivamente. Chama atenção também o percentual elevado $(33,9 \%)$ de ausências dos técnicos por licença à gestante. 
Tabela 12. Distribuição das ausências não previstas (em dias) dos trabalhadores de enfermagem, segundo categoria profissional e tipo de ausência em uma UBDS. Ribeirão Preto, agosto/1998 a julho/2002.

\begin{tabular}{|c|c|c|c|c|c|c|c|c|c|c|c|c|c|c|c|c|c|c|}
\hline \multirow{3}{*}{$\underline{\underline{\text { Categoria }}}$} & \multicolumn{18}{|c|}{ Tipo de ausência } \\
\hline & \multicolumn{2}{|c|}{$\underline{\text { injustificada }}$} & \multicolumn{2}{|c|}{ Falta abonada } & \multicolumn{2}{|c|}{ Licença Saúde } & \multicolumn{2}{|c|}{$\frac{\text { Licença Ac. }}{\text { de Trabalho }}$} & \multicolumn{2}{|c|}{$\frac{\underline{\text { Licença }}}{\underline{\text { Gestante }}}$} & \multicolumn{2}{|c|}{$\frac{\text { Licença doença }}{\text { em familiar }}$} & \multicolumn{2}{|c|}{$\frac{\text { Licença }}{\underline{\text { Prêmio }}}$} & \multicolumn{2}{|c|}{$\begin{array}{l}\frac{\text { Outras }}{\frac{\text { licenças }}{(\text { nojo, }}} \\
\frac{\text { paternidade, }}{\text { Congresso) }}\end{array}$} & \multicolumn{2}{|c|}{$\underline{\text { TOTAL }}$} \\
\hline & $\underline{\text { No }}$ & $\underline{\%}$ & $\underline{N^{0}}$ & $\underline{\%}$ & $\underline{N^{0}}$ & $\underline{\%}$ & $\underline{N^{0}}$ & $\underline{\%}$ & $\underline{N^{0}}$ & $\underline{\%}$ & $\underline{N^{0}}$ & $\underline{\%}$ & $\underline{N^{0}}$ & $\underline{\%}$ & $\underline{N^{0}}$ & $\underline{\%}$ & $\underline{N^{\circ}}$ & $\underline{\%}$ \\
\hline Enfermeiro & $\underline{6}$ & $\underline{0,82}$ & $\underline{23}$ & $\underline{3,14}$ & $\underline{399}$ & $\underline{54,43}$ & $\underline{8}$ & $\underline{1,09}$ & $\underline{120}$ & 16,37 & $\underline{32}$ & $\underline{4,37}$ & 110 & $\underline{15}$ & $\underline{35}$ & $\underline{4,77}$ & $\underline{733}$ & 100 \\
\hline Técnico & $\underline{15}$ & $\underline{4,23}$ & $\underline{3}$ & $\underline{0,85}$ & $\underline{147}$ & $\underline{41,52}$ & $\underline{0}$ & $\underline{0}$ & $\underline{120}$ & $\underline{33,9}$ & $\underline{31}$ & $\underline{8,76}$ & $\underline{15}$ & $\underline{4,24}$ & $\underline{23}$ & $\underline{6,5}$ & $\underline{354}$ & 100 \\
\hline$\underline{\text { Auxiliar }}$ & $\underline{180}$ & $\underline{5,33}$ & $\underline{480}$ & $\underline{14,21}$ & $\underline{1.545}$ & $\underline{45,75}$ & $\underline{201}$ & $\underline{5,95}$ & $\underline{284}$ & $\underline{8,41}$ & $\underline{107}$ & $\underline{3,17}$ & $\underline{480}$ & $\underline{14,21}$ & $\underline{100}$ & $\underline{2,96}$ & $\underline{3} \cdot \underline{377}$ & $\underline{100}$ \\
\hline TOTAL & 201 & $\underline{4,5}$ & $\underline{506}$ & $\underline{11,33}$ & 2.091 & 46,84 & $\underline{209}$ & $\underline{4,68}$ & $\underline{524}$ & 11,73 & $\underline{170}$ & $\underline{3,88}$ & $\underline{605}$ & $\underline{13,55}$ & $\underline{158}$ & $\underline{3,54}$ & $\underline{4.464}$ & 100 \\
\hline
\end{tabular}


Com base nos valores apresentados na tabela 12, calculamos, em relação ao total de ausências não previstas, a proporção de cada tipo de ausência.

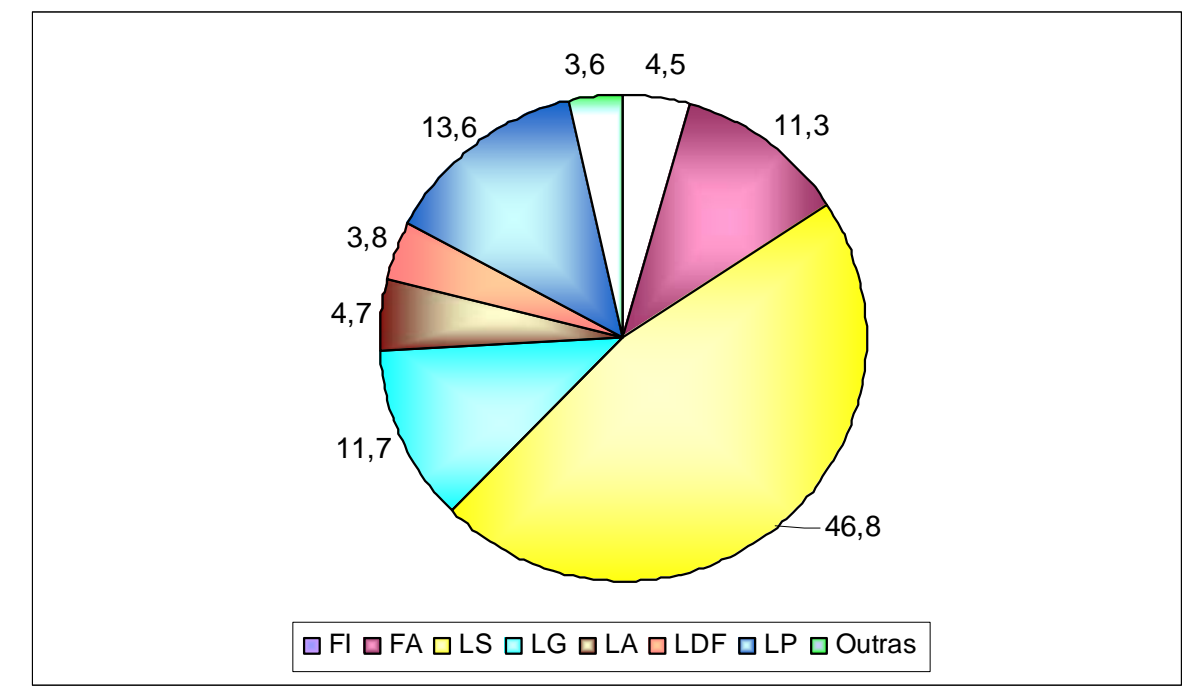

Figura 3. Proporção de ausências não previstas, segundo tipo de ausência, na UBDS, agosto/1998 a julho/2002.

\section{Legenda}

$\mathrm{FI}=$ Falta Injustificada

LS = Licença de Saúde

LA = Licença por Acidente de Trabalho

LP = Licença-Prêmio

$F A=$ Falta Abonada

LG = Licença à Gestante

LDF = Licença Doença em Familiar

Outras $=$ Nojo, Paternidade, Congresso

Robazzi et al. (1990), ao estudarem os motivos das ausências não previstas da equipe de enfermagem de uma clínica cirúrgica de um hospital público, constataram que 63,2\% eram por licença médica.

Alves (1994) constatou que as licenças médicas foram responsáveis por $75 \%$ das ausências.

Silva (1999), identificou que $72,6 \%$ dos afastamentos ocorridos 
entre os trabalhadores de enfermagem eram por motivo de doença.

Echer et al. (1999), ao estudar o absenteísmo nos trabalhadores de enfermagem numa unidade de internação cirúrgica de um hospital universitário, encontraram como motivo de ausência de maior destaque a licença de saúde, que correspondeu a 79,2\% dos afastamentos não previstos.

O percentual obtido por Posssari (2001), em um centro cirúrgico de hospital geral foi de $55,9 \%$ para as ausências por licença médica. Resultados semelhantes foram apresentados por Pavani (2000), no qual $73 \%$ das ausências não previstas da equipe de enfermagem foram motivadas por licença de saúde.

O estudo de Fugulin (2002), em sua tese de doutorado identificou que $53,5 \%$ das ausências foram ocasionadas por esse motivo. Corroborando os dados encontrados, os estudos de Farias (2003) e Laus (2003), apontaram percentuais equivalentes a $79,7 \%$ e $58,8 \%$ para as licenças de saúde.

Para Otero (1993), a maioria das ausências ao trabalho é justificada por atestado médico, entretanto isso não significa que todas essas ausências sejam sempre decorrentes de doenças.

Sobre este assunto, Valtorta et al. (1985); Alves (1996) afirmam que o atestado médico é uma válvula de escape que o trabalhador encontra para fugir de situações indesejáveis, conflituosas e até mesmo para demonstrar insatisfação.

$\mathrm{Na}$ análise realizada por Valtorta et al. (1985), os mesmos 
constaram que das licenças de saúde gozadas, somente 30\% estavam relacionadas às causas médicas e 70\% ligadas às causas sociais.

Em nosso cotidiano, temos ouvido funcionários expressarem suas insatisfações em relação às chefias, quando estas não atendem às solicitações de folga, férias e licença-prêmio no período desejado, comentando que entrarão de licença de saúde como recurso para estar ausente de suas atividades laborais, no período idealizado/planejado pelo servidor. Alguns servidores, em função de afastamentos constantes de colegas, acabam sentindo-se sobrecarregados nas atividades cotidianas e utilizam-se também de atestados como estratégia para se ausentarem do trabalho.

Silva (1996) comenta que, quando os índices de absenteísmo por doença forem elevados, indicam a necessidade de se elaborar um programa voltado à melhoria das condições de trabalho e sugere também a criação de um banco de dados para otimizar o registro das faltas, facilitando, assim, seu controle e possibilitando futuras pesquisas.

Indubitavelmente as características do trabalho de enfermagem apontadas anteriormente em nossas considerações, assim como o estresse decorrente dessa atividade, são fatores relacionados a possíveis problemas de saúde, ocasionando afastamento do trabalho.

Vários autores afirmam, entre eles, Mauro et al. (1976), que a enfermagem é uma das profissões que contribuem para preservar a vida e a saúde do homem, mas ainda não conseguiu resolver os problemas relativos à sua própria proteção. Os trabalhadores estão sujeitos à excessiva carga 
de trabalho e fadiga mais ou menos crônica.

Para Alves (1994, p.71), na enfermagem e nas instituições de saúde "o trabalhador se depara, a cada momento, com a dor humana, as condições de trabalho desfavoráveis e a expectativa de produtividade com qualidade por parte dos dirigentes...".

O percentual de licença para tratamento de saúde apurado em nosso estudo é de $46,84 \%$, o que aparentemente é inferior se for comparado aos resultados apresentados pelos autores citados. Esse resultado pode ser explicado, em parte, se considerarmos as diferenças no regime de contratação adotado pelas instituições de saúde. No caso de contrato pela CLT, o funcionário não dispõe de recursos como falta abonada, licença por motivo de doenças em pessoas da família, assim como licença-prêmio, o que pode gerar atestado médico para resolver problemas sociais.

O segundo motivo mais freqüente de ausência não prevista foi a licença-prêmio 13,55\%. Este tipo de licença só ocorre para trabalhadores do setor público contratados sob regime estatutário, assim, poucos estudos podem ser comparados ao nosso, porém dados semelhantes foram encontrados por Echer et al. (1999), que verificaram, para o grupo de enfermagem de um hospital governamental, 12,5\% de ausências devido à licença-prêmio.

Como terceira causa de ausência não prevista tem-se a licença à gestante, 11,73\%.

Silva (1983), no seu estudo em um hospital governamental, detectou que a licença à gestante respondeu por $14,4 \%$ do total do 
absenteísmo; Otero (1993) também identificou, em hospitais da Espanha, que entre 10 a 15\% dos afastamentos estavam relacionados à gestação; no estudo de Laus (2003), a proporção dessas ausências não previstas foi de $25,5 \%$.

Os percentuais de ausências relativos à licença à gestante traduzem o perfil dos integrantes da equipe de enfermagem, em geral um grupo jovem, predominantemente feminino e em fase reprodutiva.

Constatamos que a falta abonada representou o quarto motivo de absenteísmo, correspondendo a $11,33 \%$ do total de afastamentos. Também este tipo de ausência constitui prerrogativa do servidor público estatutário, não tendo sido encontrados estudos que permitam comparações.

Quanto à licença por acidente de trabalho, a proporção foi de 4,68\%. Um dos tipos de acidente de trabalho mais freqüentes na UBDS tem sido o ocasionado por material perfurocortante.

Em algumas situações, o funcionário que sofre este acidente, recusa-se a preencher a "Comunicação para Acidente de Trabalho - (CAT)" em virtude da burocracia e devido ao protocolo de se submeter à quimioprofilaxia e ao acompanhamento sorológico para hepatite e Vírus da Imunodeficiência Humana (HIV). Esse fato pode estar subestimando os dados relativos a esta ausência não prevista.

Nos estudos de Robazzi et al. (1990), o percentual encontrado para este tipo de ausência foi de 19,5\%; em Possari (2001), o afastamento por acidente de trabalho foi de 17,13\%; na investigação de Barboza (2003), 
6,3\% e, na de Laus (2003), de 12,8\%. Segundo Napoleão (1999), os acidentes de trabalho na enfermagem são subnotificados devido à: falta de conhecimento sobre o que é o acidente de trabalho, à falta de tempo para notificá-lo, à burocracia e ao medo de perder o emprego, assim como à culpa pelo ocorrido.

As faltas injustificadas representaram 4,5\% das ausências não previstas, enquanto, na pesquisa realizada por Silva (1983), esse percentual foi superior, ou seja, $14,4 \%$.

Segundo Jorge (1995, p.40), "as questões de saúde família têm gerado absenteísmo na equipe de enfermagem", nesse sentido, a licença por motivo de doença em pessoa da família cujo percentual foi de 3,88\% representou outra causa de ausência.

Souza et al. (2002), em uma unidade de Terapia Intensiva de hospital de grande porte, identificaram que $21 \%$ das ausências do pessoal de enfermagem ocorreram em função da necessidade do trabalhador acompanhar filhos e/ou esposa em situações de adoecimento.

Outras licenças (nojo, paternidade e congresso) respondem pelo menor percentual de ausências 3,54\%.

A licença congresso só é concedida ao pessoal de nível universitário, portanto, às enfermeiras. Embora sendo um direito do funcionário, essa licença foi pouco utilizada, representando para os afastamentos ocorridos nessa categoria apenas 0,68\%. Isso pode indicar o pouco interesse desses profissionais em relação ao aperfeiçoamento e à atualização. Até por falta de incentivo por não vislumbrar promoção devido à 
falta de existência de Plano de Cargos e Salários.

Cumpre lembrar que, licença-prêmio, falta abonada e licença para tratamento de doença em pessoa da família constituem afastamentos apenas concedidos a trabalhadores vinculados ao regime estatutário. Esse conjunto de afastamentos correspondeu a 28,76\%, ou seja, aproximadamente um terço do total das ausências não previstas verificadas na UBDS estudada. Constatamos que não houve afastamento por licença gala. Cabe destacar que, ao longo do período investigado, nenhum funcionário sofreu a aplicação de suspensão como medida disciplinar.

Sobre esse assunto Médici \& Oliveira (1991) comentam que no serviço público no qual vigora o estatuto da estabilidade no emprego, o nível de absenteísmo atinge altas taxas, e que os profissionais de saúde não estão sujeitos às devidas punições.

O estudo de Alves (1994) revelou que, em hospitais públicos, os índices de absenteísmo variaram de $4,78 \%$ a $8,98 \%$, e nos privados, de $0,25 \%$ a $5,44 \%$. Essa autora comenta que isso leva a inferir que pode estar ocorrendo maior controle, através de mecanismos de punição, nos hospitais privados.

No setor privado, há sempre uma preocupação acentuada com os custos e a qualidade. A otimização de recursos humanos é monitorada. É exigida eficiência dos funcionários em seu desempenho e eles recebem incentivos quanto à atualização, bem como são informados sobre a filosofia da empresa e o que se espera deles. Caso não haja correspondência por parte dos trabalhadores no que diz respeito aos padrões estabelecidos de 
assiduidade, estes são substituídos. Em contrapartida, no setor público, a questão da estabilidade no emprego associado ao fato de não haver, por parte do sistema, um acompanhamento quanto à satisfação dos usuários, avaliação de desempenho periódica dos funcionários e monitoramento dos afastamentos, o servidor tem a impressão de que a instituição trata com uma certa indiferença a questão da freqüência ao trabalho. 
6. CONSIDERAÇÕES FINAIS 
É sabido que as causas do absenteísmo não podem ser atribuídas exclusivamente à decisão individual/pessoal do trabalhador. A expressão de insatisfação e, por conseqüência, a baixa motivação para o trabalho, podem ocasionar atrasos, licenças de saúde, faltas deliberadas (injustificada, abonada) as quais podem estar vinculadas à organização do trabalho (sobrecargas), à existência ou não de processos de supervisão e às respectivas estratégias adotadas pela gerência.

$$
\text { Partindo da premissa de que é através do trabalho }
$$
desenvolvido pelas pessoas que se alcançam os resultados propostos pela organização, neste caso, atender a necessidades de saúde da população, entendemos que o absenteísmo é essencialmente um problema de gestão e neste sentido, cabe à gerência o acompanhamento e monitoramento da assiduidade de seus trabalhadores.

Para que um serviço de saúde realize intervenções no absenteísmo, é necessário em um primeiro momento conhecê-lo em sua dimensão quantitativa, isto é, mensurá-lo. Em uma segunda etapa, há que se identificar as causas desse evento, as quais revelarão nuances qualitativas que envolvem múltiplas dimensões, entre elas: as relações interpessoais e de interação no grupo de trabalho; às condições de trabalho oferecidas e os processos de trabalho desenvolvidos na instituição, que não podem ser reduzidas a dados numéricos.

Os resultados obtidos apontam que na Unidade Básica e Distrital de Saúde estudada, os índices de absenteísmo merecem ser monitorados, uma vez que, em cada ano de estudo, cada trabalhador 
ausentou-se, em média, 23 dias.

Há que se apontar ainda as dificuldades encontradas para desenvolver comparações entre os resultados desta investigação com a literatura. Um primeiro aspecto refere-se à ausência de estudos de absenteísmo em Unidades Básicas de Saúde. Os autores consultados realizaram seus estudos na área hospitalar, e, na maioria, o contrato de trabalho do pessoal de enfermagem é regido pela Consolidação das Leis do Trabalho (CLT), enquanto na unidade pesquisada vigora o regime estatutário que traz em si diferenças importantes quanto à regulamentação dos afastamentos do trabalho. Outros aspectos, a destacar, dizem respeito às distintas classificações de ausências não previstas e de equações adotadas para mensuração do evento.

Com base nos resultados alcançados e na prática profissional desenvolvida, inúmeras reflexões emergiram, entre elas, o delineamento de estratégias de atuação com vistas a monitorar/controlar o absenteísmo. Considerando os respectivos níveis de competência, sugerimos:

\section{À chefia imediata}

- realizar treinamento local para funcionários novos e informálos sobre seus direitos/deveres;

- promover a inserção no trabalho de forma sistematizada;

- procurar conhecer cada membro da equipe de modo a identificar eventuais problemas pessoais que possam interferir no seu desempenho;

- manter certa maleabilidade ao escalar os funcionários, 
procurando alocá-los em áreas que tenham maior afinidade, dentro das possibilidades do serviço;

- realizar reuniões periódicas com o grupo, a fim de tratar de assuntos inerentes ao cotidiano do processo de trabalho;

- incentivar os funcionários a participarem de cursos de atualização.

\section{À gerência local}

- compartilhar com os servidores as mudanças relativas ao atendimento e rotinas da unidade, promovendo a integração da equipe;

- informar aos funcionários sobre o impacto dos trabalhos desenvolvidos na área de abrangência do serviço;

- estimular a participação dos trabalhadores em eventos de capacitação;

- manter um estreito contato com o Sindicado dos Servidores Municipais com vistas a análise de situações pertinentes ao absenteísmo;

- propiciar encontros grupais, com profissionais capacitados, criando espaço para os trabalhadores exteriorizarem seus desejos, problemas e necessidades.

\section{À Divisão de Enfermagem}

- analisar de forma sistemática, articulada à gerência da unidade, as solicitações de remanejamento de local de trabalho dos servidores, procurando alocá-los próximo ao seu domicílio.

\section{À Divisão de Gerenciamento de Pessoal}

- implementar um sistema de informações on line que 
possibilite à Unidade de Saúde ser informada a respeito do afastamento dos servidores, a fim de providenciar substituição na escala com antecedência;

- proceder a um estudo sobre as reais causas do absenteísmo e propor um plano de ação para minimizá-lo;

- implantar e desenvolver com as gerências a avaliação de desempenho;

- agilizar, junto a órgãos competentes, a implantação do Plano de Carreira.

\section{À Divisão de Segurança e Medicina do Trabalho}

- levantar e analisar agentes insalubres na unidade e discutir propostas de intervenção.

\section{À Perícia médica}

- analisar criteriosamente os casos de afastamento freqüentes e/ou prolongados dos servidores.

\section{À Comissão Local de Saúde}

- realizar encontros periódicos com o pessoal da unidade para conhecer as dificuldades relacionadas a recursos materiais, humanos e condições de trabalho.

A realização deste estudo possibilitou mensurar o índice de absenteísmo numa Unidade Básica e Distrital de Saúde, apontando para a necessidade de outras investigações nesse campo. Os dados apurados podem constituir-se em parâmetros para estudos em outras unidades da rede básica de saúde do município de Ribeirão Preto. Além disso, permite a formulação de novas questões para investigações futuras, entre elas, a 
análise da associação entre o absenteísmo por licença de saúde dos trabalhadores de enfermagem e as condições de trabalho vigentes no seu espaço específico de atuação. 
7. REFERÊNCIAS BIBLIOGRÁFICAS 
A BUSCA da produtividade através da qualidade de vida. Gazeta Mercantil, Rio de Janeiro, 28 abr. 1998. p.1-2. Disponível em: <http://www. jsmnet.com/dippings/co428gr2.htm> Acesso em: 28 abr. 2002.

ALCALÁ, M.U.; NUNES, M.F.; KATO, T.; REIGADA, I.; SILVA, R.M.L.; KOSHIMURA, D.K. Cálculo de pessoal: estudo preliminar para o estabelecimento de quadro de pessoal de enfermagem na Superintendência Médico-Hospitalar de Urgência. São Paulo: Secretaria de Higiene e Saúde, 1982.

ALMEIDA, M.C.P.; ROCHA, J.S.Y. O saber da enfermagem e sua dimensão prática. São Paulo: Cortez, 1986. 128 p.

ANSELMI, M.L.; ANGERAMI, E.L.S.; GOMES, E.L.R. Rotatividade e condições de trabalho nos hospitais do município de Ribeirão Preto. Rev. Bras. Saúde Ocup., São Paulo, v. 23, n. 85-6, p. 31-41, set. 1997.

ANSELMI, M.L. Quadro de referência para elaboração do orçamento de enfermagem em instituições hospitalares. 2000. 134f. Tese (Livre Docência) - Escola de Enfermagem de Ribeirão Preto, Universidade de São Paulo, Ribeirão Preto, 2000.

"Sobrevivência" no emprego dos trabalhadores de enfermagem em uma instituição hospitalar pública. Rev. Latinoam. Enfermagem, Ribeirão Preto, v. 9, n. 4, p. 13-18, jul. 2001.

ALVES, M. O absenteísmo do pessoal de enfermagem nos hospitais. Rev. Gauch. Enfermagem, Porto Alegre, v. 15, n. 1/2, p. 71-5, jan./dez. 1994

As causas do absenteísmo na enfermagem: uma dimensão do sofrimento no trabalho. 1996. 175f. Tese (Doutorado) - Escola de Enfermagem, Universidade de São Paulo, São Paulo, 1996. 
ANGELO, D.A.D.; MARZIALE, M.H.P. Processo de mudanças e inovações no ambiente de trabalho: momento de reflexão para os enfermeiros. Rev. Baiana Enf., Salvador, v. 11, n. 2, p. 24-37, out. 1998.

AQUINO, E.M.L.; ARAUJO, M.J.S.; MENEZES, E.M.S.; MARINHO, L.F.B. Saúde e trabalho de mulheres profissionais de enfermagem em um hospital público de Salvador, Bahia. Rev. Bras. Enfermagem, Brasília, v. 46, n. 3-4, p. 245-57, jul./dez. 1993.

BARBOZA, D.B. Afastamentos do trabalho na enfermagem de um hospital geral no período de 1995 a 1999. 2001. 137f. Dissertação (Mestrado) - Faculdade de Medicina de São José do Rio Preto (FAMERP), São José do Rio Preto, 2001.

BARBOZA, D.B.; SOLER, Z.A.S.G. Afastamentos do trabalho na enfermagem: ocorrências com trabalhadores de um hospital de ensino. Rev. Latinoam. enfermagem, Ribeirão Preto, v. 11, n. 2, p. 177-83, mar./abr. 2003.

BEHREND, H.; POCOCK, S. Ausentismo: el caso de una empresa. Rev. Int. Trabajo. Genebra, v. 3, n. 94, p. 337-54, abr. 1976.

BEZERRA, A.L.Q. O significado da rotatividade de pessoal numa instituição de saúde privada. Rev. Bras. Enfermagem, Brasília, v. 50, n. 1, p. 107-120, jan./mar. 1997.

BELÉM, J.H.R.; GAIDZINSKI, R.R. Estudo das ausências da equipe de enfermagem. Rev. Bras. Enfermagem, Brasília, v. 51, n. 4, p. 697-708, out./dez. 1998.

BRASIL. Ministério da Saúde.Seminário de investigação sobre recursos humanos em saúde. Brasília: Ministério da Saúde, Coordenação Geral de 
Desenvolvimento de Recursos Humanos para o SUS, 1993. 49p.

- Ministério da Saúde. Projeto de Profissionalização dos trabalhadores da área de enfermagem (PROFAE). Sinais de mercado de trabalho do pessoal de enfermagem no Brasil. Brasília: Ministério da Saúde..., 1996. p. 47-72.

Ministério do Trabalho. Segurança do Trabalho e Medicina do Trabalho. 49.ed. São Paulo: Atlas, 2001.

BROOKE JÚNIOR, P.P. Beyond the Steers and Rhode model of employee attendance. Acad. Manag. Rev., Ohio, v. 2, n. 11, p. 345-61, set. 1986.

CAMPEDELLI, M.C.; TAKITO, C.; SANCINETTI, T.R.; BENKO, M.A. Cálculo de pessoal de enfermagem: competência da enfermeira. Rev. Esc. Enfermagem - USP, São Paulo, v. 21, n. 1, p. 3-15, 1987.

CARVALHO, D.C.; LIMA, E.D.R.P. Sintomas físicos de estresse na equipe de enfermagem em centro cirúrgico. Nursing, São Paulo, v. 4, n. 34, p. 3134, mar. 2001.

CERIA, C.D. Nursing absenteeism and its efeccts on quality of pacient care. J. Nurs. Adm., Billerica, v. 22, n. 12, p. 11-38, dec. 1992.

COLLA, A.G.; SOUZA, J.M.; LIBRANDI, M.Z.A.; FERNÁNDES, R.M. Comentários ao Estatuto dos Funcionários Municipais de Ribeirão Preto: Lei no 3181/76. Ribeirão Preto: Off, 1997.

COMO EU CUIDO de quem cuida? Nursing, São Paulo, n. 37, p. 12-13, Ano 4, jun. 2001.

CONSELHO FEDERAL DE ENFERMAGEM. Resolução n. 189/96. Estabelece parâmetros para dimensionamento do quadro de profissionais de 
enfermagem nas instituições de saúde. In: Conselho Regional de Enfermagem. Documentos Básicos de Enfermagem: enfermeiros, técnicos e auxiliares. São Paulo, 1997. p. 177-80.

COUTO, H.A. Absenteísmo: uma visão bem maior que a simples doença. In: Temas de saúde ocupacional. Belo Horizonte: Ergo, 1987. Cap. 2, p. 9-34.

CHIAVENATO, I. Recursos humanos. 4. ed. São Paulo: Atlas, 1997.

DANATRO, D. Ausentismo laboral de causa medica en una instituición publica. Rev. Med. Uruguay, Montevideo, v. 13, n. 2, p. 101-09, ago. 1997.

DEJOURS, C. A loucura do trabalho: estudo de psicopatologia do trabalho. 5. ed. São Paulo: Cortez/Obaré, 1992.

DISPONÍVEL em: <http:Ilwww.saude.ribeirãopreto.sp.gov.Br/ssaude/Apoio/ I16 afastamentos.htm>. Acesso em: 20 maio 2002.

ECHER, I.C.; MOURA, G.M.; MAGALHÃES, A.M.; PIOVESAN, R. Estudo do absenteísmo como variável no planejamento de recursos humanos em enfermagem. Rev. Gaúch. enferm., Porto Alegre, v. 20, n. 2, p. 65-76, jul. 1999.

FARIAS, F.A.C. Dimensionamento de pessoal de enfermagem para pronto socorro especializado em afecções cardiovasculares. 2003. $257 f$. Tese (Doutorado) - Escola de Enfermagem, Universidade de São Paulo, São Paulo, 2003.

FISCHER, F.M. Absenteísmo e acidente de trabalho entre trabalhadores em turnos de indústria automobilística. 1984. 208f. Tese (Doutorado) Faculdade de Saúde Pública, Universidade de São Paulo, São Paulo, 1984. 
FUGULIN, F.M.T. Dimensionamento de pessoal de enfermagem: avaliação do quadro de pessoal das unidades de internação de um hospital de ensino. 2002. 189f. Tese (Doutorado) - Escola de Enfermagem, Universidade de São Paulo, São Paulo, 2002.

GAIDZINSKI, R.R. Dimensionamento de pessoal de enfermagem segundo a percepção de enfermeiros que vivenciam essa prática. 1994. 258f. Tese (Doutorado) - Escola de Enfermagem, Universidade de São Paulo, São Paulo, 1994.

Dimensionamento do pessoal de enfermagem em instituições hospitalares. 1998. 118f. Tese (Livre-Docência) - Escola de Enfermagem, Universidade de São Paulo, São Paulo, 1998.

Dimensionamento do pessoal de enfermagem. In: KURGANT, P. (coord.). Administração em Enfermagem. São Paulo: EPU, 1991. Cap. 7, p. 91-6.

GRAÇA, L. The process of becoming, leaving from and returning to work [o processo de adoecer, faltar e voltar ao trabalho. Papers on Health \& Work: Absenteeism. Page 11 [on line]. Disponível em: $<$ http://www.terravista. pt/meco553/textos11.html.1999>.

HOGA, L.A.K. Cuidando do cuidador. In: CONGRESSO BRASILEIRO DE ENFERMAGEM, 50, 1998, Salvador. Anais... Salvador: ABEn, 1998. p. 27885.

JORGE, A.L. Motivos que levam os trabalhadores de enfermagem ao absenteísmo. Acta Paul. Enfermagem, São Paulo, v. 8, n. 1, p. 39-46, jan./abr. 1995.

KOIZUMI, M.S. Fundamentos metodológicos da pesquisa em enfermagem. 
Rev. Esc. Enfermagem - USP. São Paulo, Número Especial, p. 33-47, out. 1992.

LAROCQUE, D. Lábsentéisme. The Canadian Nurse/L'infirmière Canadienne, Canadá, v. 9, n. 92, p. 42-46, oct.1996.

LAUREL, A.C.; NORIEGA, M. Processo de produção e saúde: trabalho e desgaste operário. São Paulo: Hucitec, 1989.

LAUS, A.M. Dimensionamento de pessoal de enfermagem para unidades de intervenção médicas e cirúrgicas no Hospital das Clínicas da Faculdade de Medicina de Ribeirão Preto - USP. 2003. 212f. Tese (Doutorado) - Escola de Enfermagem de Ribeirão Preto, Universidade de São Paulo, Ribeirão Preto, 2003.

LEE, J.B.; ERICKSEN, L.R. The effects of a policy change on three types of absence. J. Nurs. Adm., Billerica, v. 20, n. 7/8, p. 37-40, jul./aug. 1990.

LIMA JUNIOR, J.H.V.; ÉSTHER, A.B. Transições prazer e dor no trabalho de enfermagem. Rev. Adm. Empres. (RAE), São Paulo, v. 41, n. 3, p. 20-30, jul./set. 2001.

LOPES, M.J.M. Pensando mulher, saúde, e trabalho no hospital. Rev. Gaúch. Enfermagem, Porto Alegre, v. 13, n. 1, p. 34-6, jan.1992.

MAGALHÃES, A.M.M.; DUARTE, E.R.M.; MOURA, G.M.S.S. Estudo das variáveis que participam do dimensionamento de pessoal de enfermagem em hospitais de grande porte. Rev. Gaúch. Enfermagem, Porto Alegre, v. 16, n. 1/2, p. 5-16, jan./dez. 1995.

MATTIA, A.L. Dimensionamento de pessoal de enfermagem em centro cirúrgico. 1998. 92f. Dissertação (Mestrado) - Escola de Enfermagem, 
Universidade de São Paulo, São Paulo, 1999.

MATUMOTO, S.; FORTUNA, C.M.; MISHIMA, S.M.; PEREIRA, M.J.B; DOMINGOS, N.A.M. Enfrentando a produção de cuidados no programa de saúde da família: uma experiência de supervisão de equipes. Apresentado no $V$ Congresso Nacional da Rede Unida, Londrina, 27 a 30 maio 2003.

MAURO, M.Y.C.; CORDEIRO, D.S.; YANAGUISAWA, K.; CONCEIÇÃO, J.E. Pesquisas em enfermagem: fadiga e aspectos ergonômicos no trabalho de enfermagem. Rev. Bras. Enfermagem, Brasília, v. 29, n. 4, p. 7-18, out./dez. 1976.

MÉDICl, A.C.; OLIVEIRA, F.E.B. A política de saúde no Brasil: subsídios para uma reforma. Rio de Janeiro: Instituto de Pesquisa Econômica Aplicada, 1991. (Documento de política, 6).

McDONALD, J.M.; SHAVER, A.V. An absenteeism central program. J. Nurs. Adm., Billerica, v. 11, n. 5, p. 13-18, may 1981.

MEIRA, J.B. Absenteísmo por enfermidade - sugestões para seu controle. Rev. Bras. Saúde Ocup., São Paulo, v. 10, n. 40, p. 68-76, out./dez. 1982.

MENDES, I.A.C. Convivendo e enfrentando situação de stress profissional. Rev. Latinoam. enfermagem, Ribeirão Preto, v. 9, n. 2, p. 1, mar. 2001. Editorial.

MILLER, D.S.; NORTON, V.M. Absenteeism: nursing service's albatross. J. Nurs. Adm., Billerica, v. 16, n. 3, p. 38-42, mar. 1986.

NAKAO, J.R.S.; ÉVORA, Y.D.M.; FÁVERO, N., LAUS, E. Análise dos fatores que contribuem para que funcionários do serviço de enfermagem trabalhem 
em duas instituições hospitalares. Rev. Paul. Enfermagem, São Paulo, v. 6, n. 2, p. 78-82, abr./maio/jun. 1986.

NAPOLEÃO, A.A. Causas de subnotificação de acidentes de trabalho: visão dos trabalhadores de enfermagem de um hospital do interior paulista. 1999, 95f. Dissertação (Mestrado) - Escola de Enfermagem de Ribeirão Preto, Universidade de São Paulo, Ribeirão Preto, 1999.

NOGUEIRA, J.R.S.; AZEVEDO, C.A.B. Absenteísmo - doença em mulheres. Rev. Bras. Saúde Ocup., São Paulo, v. 38, n. 10, p. 48-51, abr./maio/jun 1982.

OGUISSO, T. A mulher na força de trabalho: o trabalho da mulher enfermeira. Rev. Enfermagem UERJ, Rio de Janeiro, v. 6, n. 1, p. 309-16, jun. 1998.

ORGANIZACION Internacional del Trabajo. Absenteismo, causas y control. In: Oficina Internacional del Trabajo. Enciclopedia de Salud y Seguridad en el trabajo. Madri: Ministerio de Trabajo y Seguridad Social, 1989. v. 1, p. $5-12$.

OTERO, J.J.G. Riesgos del trabajo del personal sanitario. 2. ed. Madri: McGraw Hill, 1993.

PAVANI, L.M.D. Análise do dimensionamento de pessoal de enfermagem na unidade de pós-operatório de cirurgia cardíaca em um hospital universitário especializado em cardiologia. 2000, $134 \mathrm{f}$. Dissertação (Mestrado) - Escola de Enfermagem, Universidade de São Paulo, São Paulo, 2000.

PEGORARO, I.B. Níveis de stress em trabalhadores em unidades distritais de saúde: uma realidade preocupante. 2002. 188f. Dissertação 
(Mestrado) - Escola de Enfermagem de Ribeirão Preto, Universidade de São Paulo, Ribeirão Preto, 2002.

PEREIRA, M.G. Epidemiologia: teoria e prática. 6. ed. Rio de Janeiro: Guanabara Koogan, 2002.

PINTO, I.C. Os sistemas públicos de informação em saúde na tomada de decisão - rede básica de saúde do município de Ribeirão Preto-SP. 1999. 317f. Tese (Doutorado) - Escola de Enfermagem de Ribeirão Preto, Universidade de São Paulo, Ribeirão Preto, 1999.

POLIT, D.F.; HUNGLER, B.P. Fundamentos de pesquisa em enfermagem. 3.ed. Porto Alegre: Artes Médicas, 1995.

POSSARI, J.F. Dimensionamento de pessoal de enfermagem em centro cirúrgico no período transoperatório: estudo das horas de assistência, segundo o porte cirúrgico. 2001. 140f. Dissertação (Mestrado) - Escola de Enfermagem, Universidade de São Paulo, São Paulo, 2001.

QUICK, T.C.; LAPERTOSA, J.B. Análise do absenteísmo em usina siderúrgica. Rev. Bras. Saúde Ocup., São Paulo, v. 10, n. 40, p. 62-7, out./dez. 1982.

REID, W.M.; SMITH, S.E. Elements of a comprehensive absenteeism control program. AAOHN J., Atlanta, v. 41, n. 2, p. 90-5, feb. 1993.

RIBEIRÃO PRETO. Prefeitura Municipal de Ribeirão Preto. Secretaria da Saúde. Plano de Saúde - atualização período 2001 a 2004. Ribeirão Preto, 2001.Mimeografado/

ROBAZZI, M.L.C.C.; MARZIALE, M.H.P. Alguns problemas ocupacionais decorrentes do trabalho de enfermagem no Brasil. Rev. Bras. Enf., Brasília, 
v. 52, n. 3, p. 331-38, jul./set. 1999.

ROBAZZI, M.L.C.C.; PANACCHINI, S.R.; GIR, E.; SANTOS, W.D.F.; MARIYA, T.M. Serviço de enfermagem: um estudo sobre absenteísmo. Rev. Bras. Saúde Ocup. São Paulo, v. 18, n .69, p. 65-70, jan./fev./mar. 1990.

SANTOS, M.S.A. A (in)satisfação do enfermeiro no trabalho: implicações para o gerenciamento das ações de enfermagem - Aspectos teóricos. 1999, 135f. Dissertação (Mestrado) - Escola de Enfermagem de Ribeirão Preto, Universidade de São Paulo, Ribeirão Preto, 1999.

SANTOS, S.R. Cálculo de pessoal de enfermagem: estudo de dois métodos. Rev. Esc. Enfermagem USP, São Paulo, v. 26, n. 2, p. 137-54, ago. 1992.

SILVA, M.P. Absenteísmo grande problema das chefias de enfermagem. Rev. Gaúch. Enfermagem, Porto Alegre, v .4, n. 1, p. 85-98, jan. 1983.

SILVA, D.M.P.P. O adoecer dos trabalhadores de enfermagem: estudo dos problemas de saúde responsáveis pelo absenteísmo - doença em um hospital universitário. 1999. 140f. Dissertação (Mestrado) - Escola de Enfermagem de Ribeirão Preto, Universidade de São Paulo, Ribeirão Preto, 1999.

SILVA, D.M.P.P.; MARZIALE, M.H.P. Absenteísmo de trabalhadores de enfermagem em um hospital universitário. Revista latinoam. enfermagem, Ribeirão Preto, v. 8, n. 5, p. 44-51, out. 2000.

SILVA, V.E.F. O desgaste do trabalhador de enfermagem: estudo da relação de trabalho de enfermagem e saúde do trabalhador. São Paulo, 1996. 235f. Tese (Doutorado) - Escola de Enfermagem, Universidade de São Paulo, São Paulo, 1996. 
SOUZA, S.R.O.S.; ALMEIDA, J.F.; SILVA, M.J.; NEVES, M.C. Absenteísmo de enfermagem em Unidade de Terapia Intensiva de Adulto. Rio de Janeiro, 2002. Disponível em: <http://www.alass.org./es/Actas/57 - Br.doc. Acesso em: 5 maio 2002.

SOBRINHO, T.G. Controle do absenteísmo. Belo Horizonte, 2002. Disponível em: <http://tgs.med.br/tech_produtos_6.htm>. Acesso em: 28 abr. 2002.

SONG, R.; DALY, B.J.; RUDY, E.B., DOUGLAS, S.; DYER, M.A. Nurse's job satisfaction, absenteeism, and turnover after implementing a special care unit practice model. Res Nurs Health, New York, v. 20, n. 5, p. 443-52, ago. 1997.

SPÍNDOLA, T. Mulher, mãe e trabalhadora de enfermagem. Rev. Esc. Enfermagem USP, São Paulo, v. 34, n. 4, p. 354-61, dez. 2000.

STEAGALL-GOMES, D.L. Estudo de riscos à saúde das pessoas que trabalham na enfermagem hospitalar. Rev. Paul. Hosp., São Paulo, v. 34, n. 4-6, p. 85-93, jun. 1986.

TANOS, M.A.A.; MASSAROLO, M.C.K.B.; GAIDZINSKI, R.R. Dimensionamento de pessoal de enfermagem em uma unidade especializada em transplante de fígado: comparação do real com o preconizado. Rev. Esc. Enfermagem USP, São Paulo, v. 34, n. 4, p. $376-$ 82, dez. 2000.

TRANQUITELLI, A.M. Estudo prospectivo para determinação do número de horas de cuidados diretos de enfermagem em uma Unidade de Terapia Intensiva Geral. 1999. 85f. Dissertação (Mestrado) - Escola de Enfermagem, Universidade de São Paulo, São Paulo, 1999. 
UETI, M.F. SHIOTSU, C.H.; HIGUCHI, C.M.; CÉSAR, C.C.F.; IWAKURA, K.H.; FRANCO, L.H.R.O. Metodologia para cálculo de pessoal de enfermagem: documento preliminar. São Paulo: Secretaria de Estado da Saúde. Centro de Apoio ao Desenvolvimento de Assistência Integral à Saúde - CADAIS, 1991. Mimeografado/

VALTORTA, A.; SIDI, E.; BIANCHI, S.C.L. Estudo do absentismo médico num hospital de grande porte. Rev. Bras. Saúde Ocup., São Paulo, v. 13, n. 51, p. 55-61, jul./ago./set. 1985. 


\section{ANEXOS}




\section{ANEXO 1}

LEVANTAMENTO DAS AUSÊNCIAS NÃO PREVISTAS DOS TRABALHADORES DE ENFERMAGEM

DE UMA UNIDADE BÁSICA E DISTRITAL DE SAÚDE

UNIDADE:

MÊS:

\begin{tabular}{|l|l|l|l|l|l|l|l|l|l|l|l|l|}
\hline \multirow{2}{*}{$\begin{array}{c}\text { Categoria } \\
\text { Profissional }\end{array}$} & $\begin{array}{c}\text { Quantidade } \\
\text { Pessoal }\end{array}$ & $\begin{array}{c}\text { Falta } \\
\text { Injustificada }\end{array}$ & $\begin{array}{c}\text { Falta } \\
\text { Abonada }\end{array}$ & $\begin{array}{c}\text { Licença } \\
\text { Saúde }\end{array}$ & $\begin{array}{c}\text { Licença } \\
\text { Ac. De } \\
\text { Trabalho }\end{array}$ & $\begin{array}{c}\text { Licença } \\
\text { Gestante }\end{array}$ & $\begin{array}{c}\text { Licença } \\
\text { Doença } \\
\text { em } \\
\text { Familiar }\end{array}$ & $\begin{array}{c}\text { Licença } \\
\text { Nojo }\end{array}$ & $\begin{array}{c}\text { Licença } \\
\text { Prêmio }\end{array}$ & $\begin{array}{c}\text { Licença } \\
\text { Paternidade }\end{array}$ & $\begin{array}{c}\text { Licença } \\
\text { Congresso }\end{array}$ & Suspensão \\
\hline Enfermeiro & & & & & & & & & & & & \\
\hline Técnico & & & & & & & & & & & & \\
\hline Auxiliar & & & & & & & & & & & & \\
\hline TOTAL & & & & & & & & & & & & \\
\hline
\end{tabular}


ANEXO 2

\section{CRITÉRIOS PARA LEVANTAMENTO DAS AUSÊNCIAS NÃO PREVISTAS DA EQUIPE DE ENFERMAGEM}

QUANTIDADE DE PESSOAL: Identificar nas escalas mensais o número de funcionários da categoria.

DEMISSÕES: Se o funcionário até o $25^{\circ}$ dia do mês deverá ser incluído no número total de funcionários, caso contrário deverá ser excluído.

FALTAS: Considerar todos os tipos de faltas, inclusive as abonadas. As faltas são referentes ao período de 6 horas.

LICENÇAS: Considerar o número de dias não trabalhados. 
ANEXO 3 
ANEXO 4 


\section{AUTORIZAÇÃo}

Autorizo a reprodução e/ou divulgação total ou parcial da presente obra, por qualquer meio convencional ou eletrônico, desde que seja citada a fonte.

Nome de Autora: Gilza Marques do Nascimento

Assinatura da Autora:

Instituição: Universidade de São Paulo

Local: Escola de Enfermagem de Ribeirão Preto

Endereço: Av. Bandeirantes, 3900

E-mail: gilza@eerp.usp.br 